\title{
Make/Shift - A CReAtive Community ProjeCt
}

by

\author{
Natalie Doroslovac \\ B. Arch. Sci. 2012 \\ Ryerson University
}

\author{
A thesis \\ presented to Ryerson University \\ in partial fulfillment of the \\ requirements for the degree of \\ Master of Architecture \\ in the Program of Architecture
}

Toronto, Ontario, Canada, 2015

C)Natalie Doroslovac 2015 


\section{AUTHOR'S DECLARATION}

I hereby declare that I am the sole author of this thesis. This is a true copy of the thesis, including any required final revisions, as accepted by my examiners.

I authorize Ryerson University to lend this thesis to other institutions or individuals for the purpose of scholarly research.

I further authorize Ryerson University to reproduce this thesis by photocopying or by other means, in total or in part, at the request of other institutions or individuals for the purpose of scholarly research.

I understand that my thesis may be made electronically available to the public. 
Make/Shift - a Creative Community Project

Natalie Doroslovac

Master of Architecture 2015

Ryerson University - Architecture

\begin{abstract}
This thesis project is a contextual response, using physical, social and economic conditions of a site in a particularly provoking city to explore spatial-programmatic architectural responses. The Creative Community is a response to the problems prevalent in post-industrial cities like Detroit; it is a city with an exceptionally striking building stock that lacks social and economic prosperity. Blight is compounded by low density, however this research suggests that this cycle could possibly be broken by grassroots, nodal intensification at the neighbourhood level.

Built precedents and industrial city research will form the dialogue of the thesis. A response formulated to engage with a 1930's factory and its surroundings will be the culminating Design Project. This thesis project attempts to crystallize an architectonic vision that highlights the industrial heritage of the city while projecting future economic trends in the knowledge industry by tapping into the creative energy of a historically vibrant community.
\end{abstract}

Key words -

Adaptive reuse, creative community, industrial heritage 


\section{ACKNOWLEDGEMENTS}

I would like to thank my Supervisor and mentor Edwatd Wójs for his insight into all things; Robert Coelho - for his sage advice; and Chris Ryan, for his unwavering support. 


\section{DEDICATION}

This Thesis Project is dedicated to my parents, whose limitless support made this work possible. 


\section{TABLE OF CONTENTS}

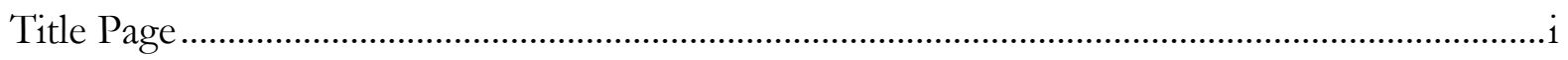

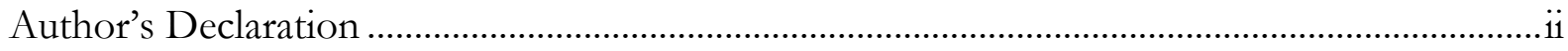

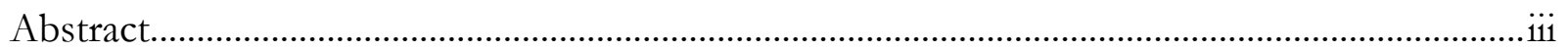

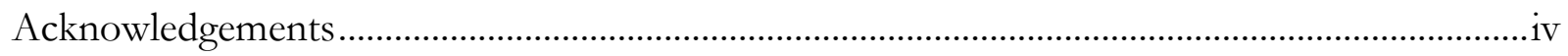

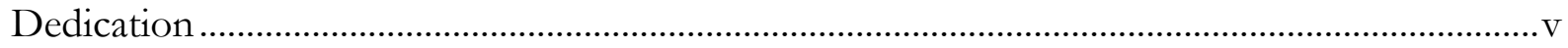

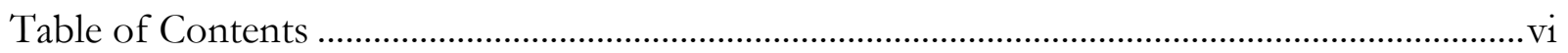

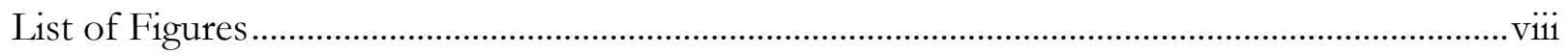

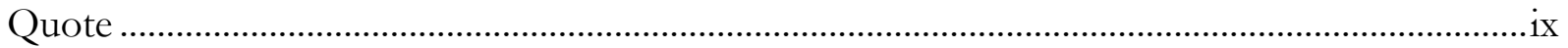

\section{PART 1 | INTRODUCTION}

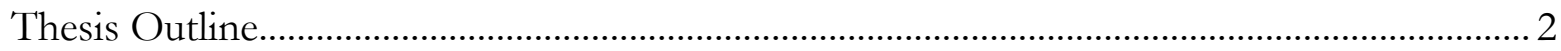

Historical Background

The Situation

Research Question

\section{PART 2 | RESEARCH}

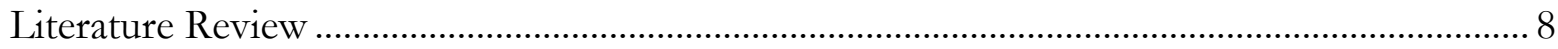

Theoretical Research

Adaptive Reuse

Modernity as the Life and Death of Motor City

Maintenance of Traditional Industry for Community Growth

Program Development.

Economic Considerations

Creative Programming

Creative Spaces

The Creative Community Project

Case Studies

Pittsburgh

Bernard Tschumi's FRESNOY

The Ljubljana City Museum by OFIS Architects

Architecture Firm's Office and Exhibition Space in Shanghai

METU MODSIM by Yazgan Design Architecture

Business Incubator Training Centre by H2O Architects

Trade School in Switzerland

Schulhaus Bruggerstrasse by Burkard Meyer 


\section{PART 3 | DESIGN}

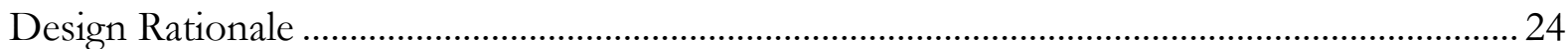

Site

Client

Technical Site Requirements

Contextual Site Requirements

Program Elements

The Designer and the Craftsman

Site Analysis

Conceptual Organization

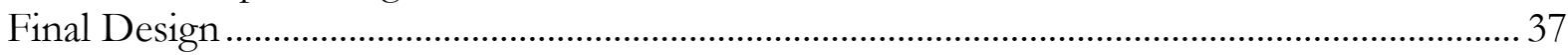

Integration/Mediation

Formal Concept and Materiality

Lighting Concept

Landscape

Memory

Community

Unique Elements

\section{PART 4 | COMMENTARY}

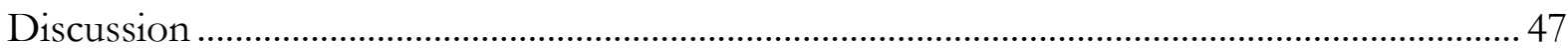

Adaptive Reuse and Continuity

Limitations

Conclusions

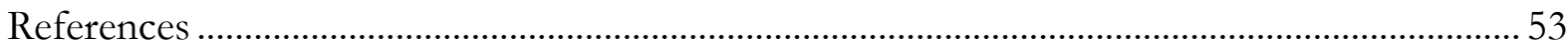




\section{LIST OF FIGURES}

Figure 1 - Map of Detroit

Figure 2 - Maps of Detroit Neighbourhoods

Figure 3 - Population Change in Detroit

Figure 4 - Examples of Craft Programs

Figure 5 - Plan Diagram of the Ljubljana City Museum

Figure 6 - Plan Diagram of an Architecture Firm's Office in Shanghai

Figure 7 - Interior Courtyard of METU MODSIM

Figure 8 - Images of Business Incubator Training Centre

Figure 9 - Schulhaus Bruggerstrasse

Figure 10 - Parti diagram

Figure 11 - South elevation of existing factory

Figure 12 - Manual Carving Area

Figure 13 - Interior view of existing factory

Figure 14 - Existing Site Plan

Figure 15 - Rendering: Stone yard and receiving entrance

Figure 16 - Rendering: Front entry of school

Figure 17 - Rendering: Interior of school lobby

Figure 18 - Rendering: Factory floor view of school volumes

Figure 19 - Model of existing building and initial formal concept

Figure 20 - Section D and West elevation

Figure 21 - Floor 1 plan

Figure 22 - Floor 2 plan

Figure 23 - Historic lathe

Figure 24 - Rendering: Townhouse residences

Figure 25 - Rendering: Lecture hall

Figure 26 - Sections A, B and C

Figure 27 - Rendering: Second floor circulation space 
Architecture emancipates us from the embrace of the present and allows us to experience the slow, bealing flow of time. Buildings and cities are instruments and museums of time. They enable us to see and understand the passing of history, and to participate in time cycles that surpass individual life. (Pallasmaa, 2005) 


\section{PART 1 | INTRODUCTION}

This thesis project was initially conceived as an exploration of disused historic structures, with the intention of studying old buildings and their physical adaptations to inform contemporary architecture. Particularly fascinating in this initial inquiry were those buildings related to industrial uses; the material quality of buildings during the economic boom of the 1920's is so desirable today. In its completion, this thesis became an investigation into postindustrial cities; specifically, the remains of buildings and the inherent urban organization caused by massive growth that, after the industrial collapse, negatively affects people that live and work there.

This site of this thesis is Detroit, where the disintegration of the systems put in place during the modern era has left the city barren, with crime plaguing abandoned land and structures. A historical background on the city of Detroit will be followed by a literature review composed of the analysis of theoretical writings and practical case studies. On an architectural level, the project explores the dialectic between new and old - both physically and programmatically, with a focus on the changing nature of economy and industry. The point of departure for the project was a synchronistic request from a business owner in Detroit for ideas to improve his business by addressing the surrounding neighbourhood. The site visit taken in October 2013 revealed a number of concerns about the building itself and the surrounding neighbourhood. Further research led to the objectives outlined later, which will inform the resulting architectural studies and culminating design.

A study of the 1930's factory and its surroundings will lead to a hypothetical projection of an architectural and programmatic design project. The factory, which currently hosts a limestone product manufacturing company called Roman Stone Works, is situated in one of 
Detroit's many industrial nodes flanked by residential neighbourhoods. The site is a fairly typical example of the urban condition outside of the downtown. This thesis will explore how architecture can engage with the existing economic, physical and social structures to stimulate a neighbourhood. The project attempts to reconcile the site's hostile outlook, by precipitating a range of programming from workweek industrial activity, to commercial and educational programs that can take place throughout the evening and on weekends. The definition of the project scope will be discussed further, in the site analysis portion of this thesis project.

\section{Thesis Outline}

This thesis project is a contextual response. It uses the conditions of the chosen site to provoke spatial and programmatic architectural decisions. Also included is research outside of the spatial, studying socio-cultural and historic phenomena. These have helped to inform the project, developing for the site a sensitive yet compelling image for the future of communities that have been affected by the changing economic outlook of manufacturing industries. The project encompasses the study of urban growth and decay, building reuse, healthy communities, and economic and social sustainability. Architectural case studies of successfully adapted historic buildings have resulted in a number of strategies to articulate the interactions between old and new. Other case studies were chosen based on their organization. In particular training centres and trade schools were chosen to explore their capacity to exhibit qualities of interactive, dynamic, and collaborative space.

Part 1 consists of relevant background and historical information, and the formulated research question. The chapters of Part 2 form the body of research, containing more information on Detroit and the rationale for programming the project, a literature review

including case studies and a discussion of important concepts drawn from the body of research. 
Part 3 encompasses the design studies and resulting project, reflecting the concepts of the thesis. Part 4 provides commentary on the conclusions of the thesis including results, limitations and a projection for further research.

\section{Historical Background}

Detroit is known as Motor City. The home of Motown and quite possibly the greatest collection of Art Deco buildings in any city in America; it is the birthplace of the assembly line and was America's Arsenal of Democracy during the Second World War (Binelli, 2012). Its population and industrial boom occurred quickly. Modernity is embedded in the growth of Detroit with industry taking over and the motorcar becoming a symbol of the American Dream. In 1935, Le Corbusier visited the city, touring Ford's River Rouge plant and considering the possibility of architecture on the mass-produced scale (Binelli, 2012).

Detroit's spatial layout was greatly influenced by choices made in the early $19^{\text {th }}$ century. In June 1805, a fire devastated the city. Michigan Territory was appointed a Chief Justice, Augustus Woodward, who proposed a radial plan for the city. Portions were implemented, including the five main radial streets; from west to east they were Michigan, Grand River, Woodward, Gratiot and Jefferson (Bennett, 1915). This radial growth was matched by industrial growth, and the cycle of growth and wealth cemented the city's dependence on the motorcar, as both an economic pillar and a way of life. The city became known for the high wages for bluecollar workers, who flocked to the city for work. Although most known for the connection to the automobile industry, Detroit also had historic brewing companies and furniture builders, as

well as oil refineries and steel mills (Sugrue, 1996). The site of this thesis was a prior steel slitting factory. 


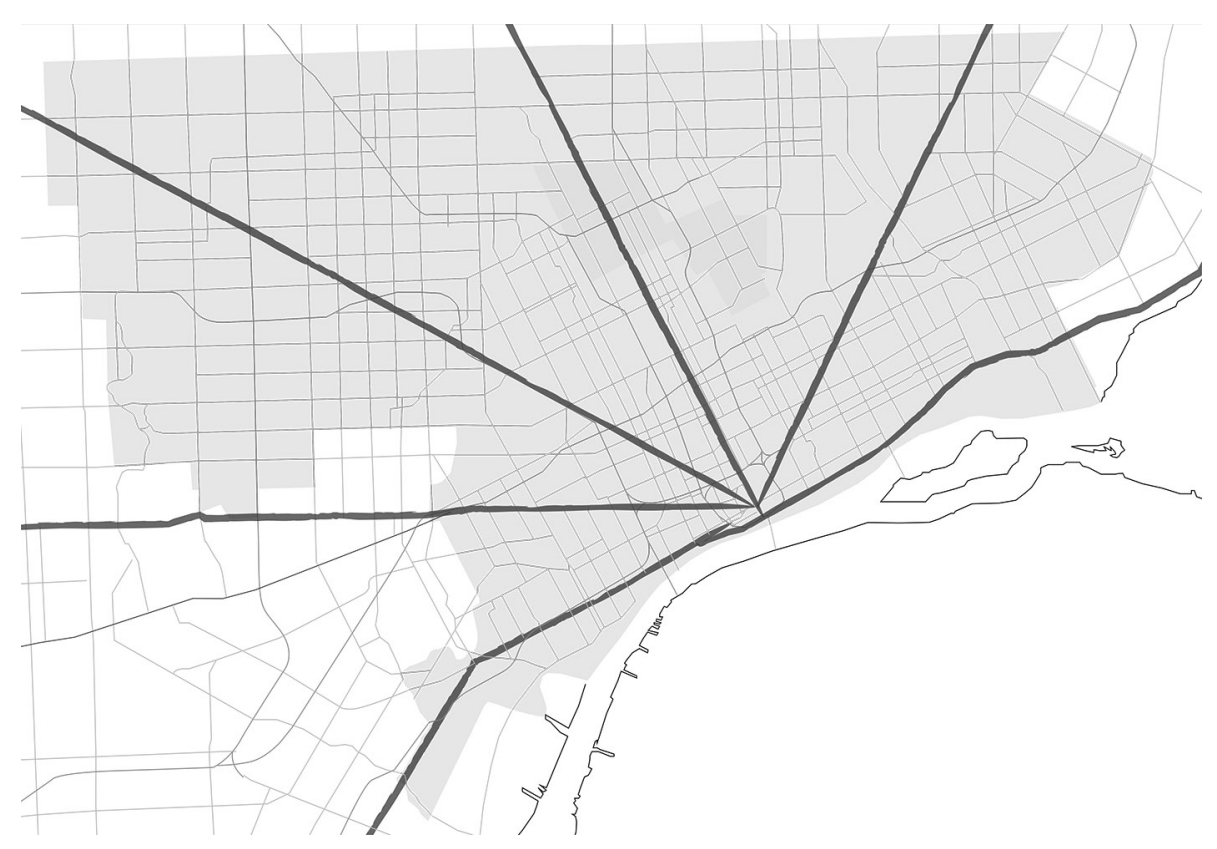

Figure 1 - map of Detroit

In the 1950's, several recessions hit the automotive industry particularly hard. All industrial cities in Northeastern United States struggled as companies relied less on central locations, moving instead to states in the lower wage paying South and growing markets in the West (Sugrue, 1996). The suburban lifestyle grew, and the city began to feel the loss of an urban middle class-manufacturing tax base. The City of Detroit has experienced a steady deterioration and loss of population, which has quite possibly plateaued at around 700000 residents. Among the political and racial concerns that are complex, there have been leadership choices that have been blamed for some of the city's financial problems. The task of stopping the urban deterioration is daunting, if not impossible, as the city faces bankruptcy and has sold massive amounts of property; enough to inspire the website detailing foreclosure and property auctions called Why Don't We Own This.

An artistic revolution is already occurring in Detroit. There is already a strong sporting and musical culture, that has every opportunity to grow. The urban scale discussed in the 
research portion of this thesis suggests that the city may, in the future, reach a tipping point for its rebirth if the cultural aspects of the city are expanded and if more jobs are created within the city limits. A strong musical culture is cited by Florida in defining the authenticity of a place, which is a draw for creative talent. The city is unabashedly authentic, with a rich history of musical talent and its own sound.

The building project designed for this thesis is an exploration into the type of architectural, economic and social project may grow and foster a community in Detroit. This bottom up approach is viable in a neighbourhood where some businesses are achieving success, are relatively high in levels of employment and have an existing industrial pulse. This area is likely to improve in terms of security due to increased traffic and lower levels of vacancy with the implementation of this project.

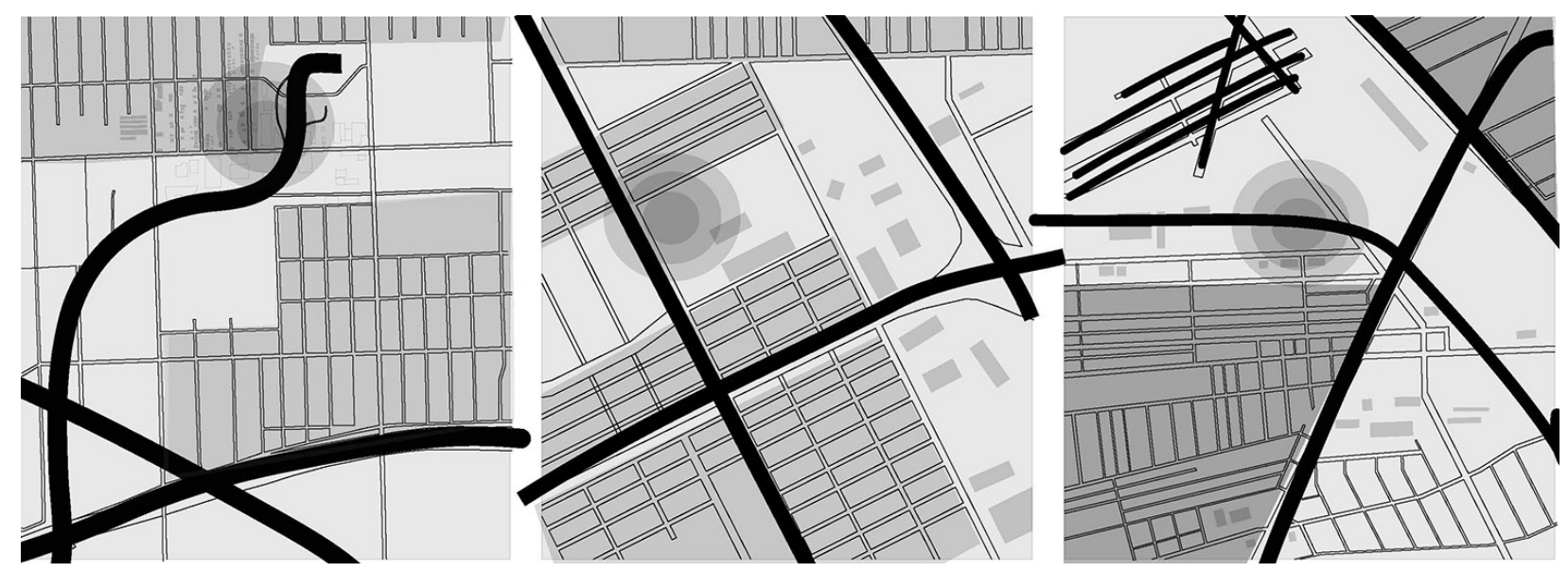

Figure 2 - maps showing the intersection of the industrial and residential areas by modes of transportation. Left: the node represents the site of this thesis. Middle and right: two other abandoned factories.

\section{The Situation}

Environmental sensitivity. While the population grows, fuel prices rise, old growth forests dwindle and increasing areas of land are used for agriculture and farming, building materials and construction will become more expensive. In time, new materials will dominate 
the market and certain materials will be prohibitive in cost. At the same time, technology is making possible so many material advancements that have the potential to re-integrate longevity in architecture. By meshing old and new in adaptive reuse projects, the potentials of these materials in terms of sustainability, efficiency and quality can be tested. In this project, the urban streetscape will be addressed with landscape elements that acknowledge the heat island effect and drainage; while helping to contribute to the identity of the chosen neighbourhood. At the largest scale, the city becomes testing ground for architectural agency using the vehicle of reuse for increasing social, economic and environmental sustainability.

Historic continuity. Roman Stone Works has roots in a Canadian stone company called Arriscraft based in Cambridge, Ontario. The parallel company's extension to Detroit allowed expansion further into the Unites States, while still maintaining proximity to its clientele in Southwestern Ontario. Detroit has a demand for limestone, which is a prevalent material used in architecture and landscaping, and in both new construction and for the renovation of facades and paving.

Although the city proper is somewhat stagnant, surrounding areas are thriving, and not coincidentally. Movement of the population from the city to the suburbs is a well-known and documented phenomenon of the 20th and 21st centuries. Sprawl is one facet of this issue, but the more specific nature of so-called shrinking cities is particularly problematic across the rust belt and in Europe. The loss of manufacturing to growing countries in Asia and the predominance of foreign products in North America result in former industry communities breaking up as workers follow opportunity elsewhere.

The existing building in question was constructed between 1935 and 1950, expanding to allow for growth in its production of steel as a slitting plant. Today, the concern is how the 
building can further improve and expand to project further success for the business. The possibility of further deterioration of buildings in the neighbourhood is a growing concern that will be addressed in this thesis with the development of a neighbourhood anchor. Today in Detroit and elsewhere, manufacturing is very different than it was in the 1930's. The Creative Class was defined by Richard Florida, who points to creativity as one of the most valued skills in today's economy. This project addresses these concerns by developing a program that takes advantage of the changing nature of industry, while being sensitive to the site and existing building and its operations. Because it is an extreme example of urban change, Detroit is an ideal city to be looked to for inspiration and as a testing ground for architectural interventions.

\section{Research Question}

An economy in flux results in the decay of architecture whose bones remain striking and immediate; how can these be muscled and fleshed to face the future of industry, and, more sensitively, how can citizens become engaged with them to reinforce communities and reestablish networks of urban density? 


\section{PART 2 | LITERATURE REVIEW}

This literature review is broken into two parts; the first encompasses a discussion of theoretical positions that have influenced this project, and the second develops and interprets these and other concepts into architectural strategies that pertain to the program development and physical strategies of the project.

\section{Theoretical Research}

This thesis project is an architectural response - at the level of one adaptive reuse project - to the varied and deep problems of Detroit. This research has come together like the blast of a bomb; a point of departure has exploded into a realm of research including industrial heritage, economic resiliency and adaptive reuse, to precipitate a project that is dependant on the very specific nature of the place. Hopefully, this project will shed light on the nature of industrial cities and their inherent complexities.

Bernard Tschumi's Architecture and Disjunction posits that while post-modern work in other fields seeks to find authentic alternatives to the modern, in architecture, it instead provides a more agreeable alternative. As a city, Detroit has broken down after its initial success a

productive economic hub. The modern industrial era made it. The globalized post-modern economy has left it deconstructed. This dichotomy points to a dialectic between the traditional and the contemporary, which will become evident in this project.

\section{Adaptive Reuse}

Structures have been plundered, reused and appropriated since the beginning of civilization. War and unrest would often result in the changing claim on land and buildings, some of which would be destroyed while others would be appropriated for similar or entirely 
different purposes. The question of quality and longevity is one that comes up in the comparison of building reuse and new construction. Architecture has lost its quality of permanence, in lieu of bottom lines and quick construction timelines. From the days of the pyramids to the Roman Coliseum, we have shifted into this era of technology and globalization, where place is less important and instantaneousness is the norm. Speed has changed the world. The Internet, air travel and the emergence of the knowledge industry have changed the nature of cities and lifestyles. Because of these changes over time, the stock of buildings that have the integrity to be reused and adapted is shrinking.

Historically, the question of building preservation has been much debated. "Boito lays out a theory of conservation that rejects the dualism between the stylistic restoration school of Viollet - Le - Duc and the pure conservation school of John Ruskin and the Society for the Protection of Ancient Buildings.” (Boito \& Birignani, 2009, p. 69). Viollet-le-Duc was a romantic historicist who wanted buildings restored the way they were meant originally, by the architect. Ruskin preferred historic honesty and believed that restoration is destructive. He only believed in the strict preservation and conservation of the structures left. Boito's theory is against this dialectic: he proposes maintenance but not deception, and a more scientific approach where the documentation of all changes and work would be maintained and even displayed, wherever possible. Today, preservation is important but is not always done. Adaptive reuse is an alternative that can address both environmental and cultural needs.

Adaptive building reuse is growing in number and popularity, and "this type of reuse has been carried out in the name of an ecologically grounded conservation of resources and/or in opposition to the monotony of contemporary materials and forms. Thus the appreciation of spolia can be economically and ecologically determined, but also aesthetically motivated..." 
(Meier, 2011, p. 225). The aesthetic of old building and materials are appreciated for their beauty but also for their cultural, nostalgic imagery.

In buildings that incorporate spolia - building materials or components from historic structures - the consensus is that although the reused items are obviously added to the design as some sort of historical reference, they also inform the design of the rest of the design; structural and spatial effects can be seen. In Spolia in Contemporary Architecture, Meier states that the arched windows "also play a very significant role in determining the structure and the character of the whole." (p. 232) The author suggests that the use of spolia has increased with the increased discussion of place referencing the idea of the genius loci by Christian Norberg-Schulz. The use of spolia - old architectural materials or components - in recent architecture is "meant to testify to a local continuity" (p. 235). With this in mind, the design portion of this project will use the existing structure for inspiration, while renovating the existing structure to allow for its continuing use.

\section{Modernity as the Life and Death of Motor City}

Detroit's motto, coined after a destructive 19th century fire is speramus meliora; resurget cineribus - or - we hope for better days; it shall rise from the ashes (Wollen \& Kerr, 2002). Never has the statement been more appropriate; it was achievable then, but does the city have a chance for another resurgence now? Businesses and political leaders are hopeful - it is a testament to this that the Renaissance Centre is named such. Unfortunately, the renaissance of Detroit is more likely to surface as a slow restructuring rather than a swift turnaround brought about by a few million-dollar projects.

Detroit is a city that has lost its rationality as a result of the loss of the modern rules that it was grown by - both economically and physically. The landscape of industry is geographically 
mobile. In the urban layout, rail systems that were so important as a driver of products and money have fallen into disuse. The peak of the city's population was 1.85 million in 1950 . The decline of population has left shells of buildings and vacant lots that are returning to an unkempt state; many of these are adjacent to neighbourhoods that are holding on to the hope that things will improve.

The automobile for the masses was made possible by the assembly line that Ford helped disseminate. The landscape of Detroit is a result of it. Over time, the disintegration of the city's buildings and infrastructure is happening due to types of systematic, but incoherent forces (Tschumi, 1996). These forces are constant and changing, and new patterns of development can be seen in maps that show a slow but sure downtown population growth in cities such as Detroit, Chicago and Pittsburgh (see Figure 3). In Detroit, low cost realty draws artists, who are followed by food establishments and shops.

Tschumi's theory of disjunctive architecture disregards both the self and the client in an attempt to define a universal design process. Materiality is left out of discussion as architecture is really "in its solids and voids, its spatial sequences, its articulations, its collisions" (Tschumi, 1996 p. 110). This logic of this statement is based on the idea that architecture as an absolute idea is material-less. In a vacuum, this could be true but not in the physical world. In projects dealing with old buildings, material means everything. More appropriate ideas of materiality have been articulated by Peter Zumpthor, who has humanistic ideas about the senses; where materials are absolutely necessary to shape spaces, impart lighting qualities, and reveal structural connections. The notion of immaterial architecture is problematic, and Detroit is a good place to witness that architecture is not forever. In its functional existence - when it is built with materials - it is vulnerable to the effects of time. 


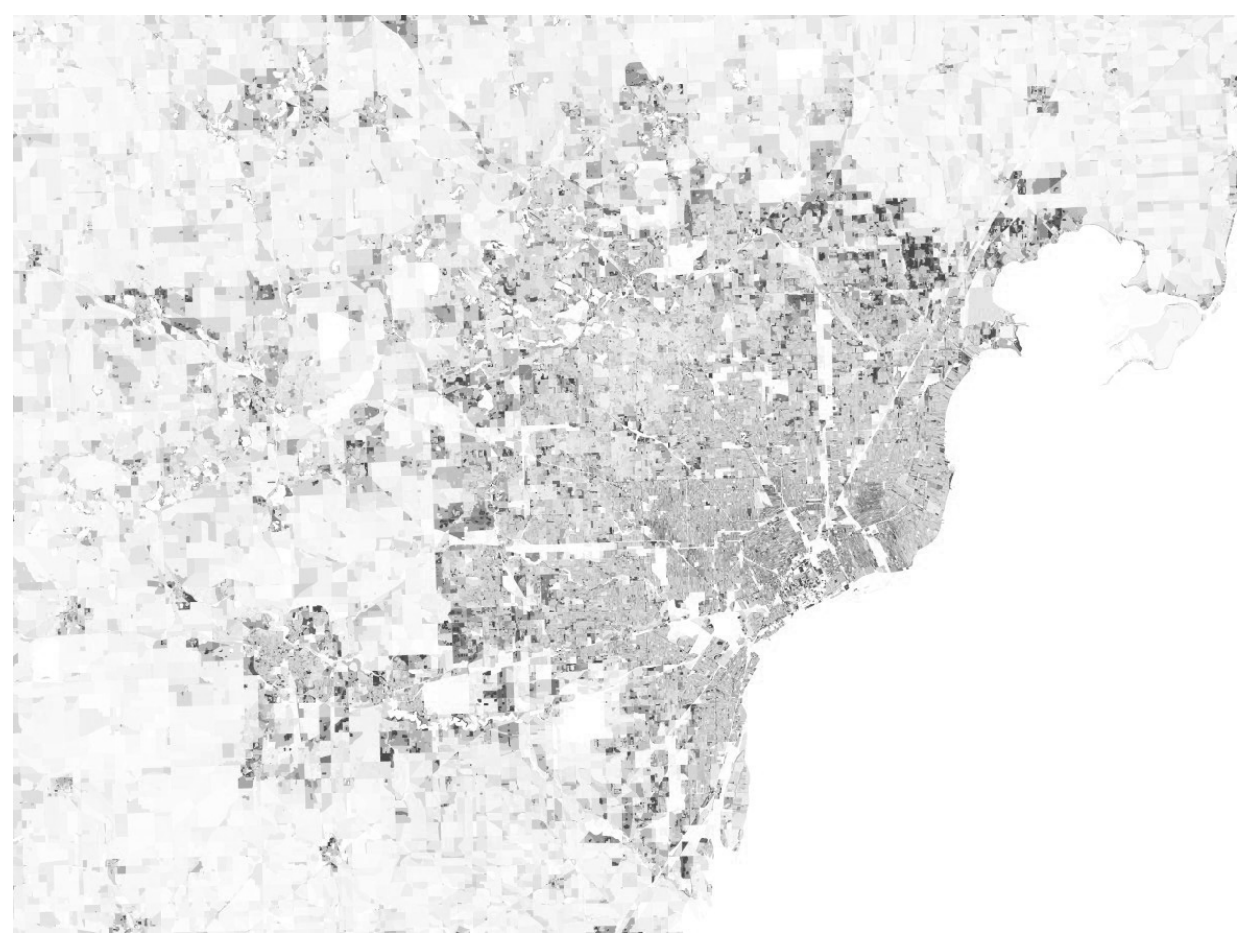

Figure 3 - Population change in Detroit

\section{Maintenance of Traditional Industry for Community Growth}

In the United Kingdom, the Prince's Foundation for Building Community is charity that focuses on the coherent growth of sustainable communities through education, craft and design. At its inception it was called the Institute of Architecture. More recently, it has focused on filling the need for skilled craftsmen such as thatchers, carpenters and masons, who are required to maintain existing vernacular architecture. The Foundation also runs programs in North America and the Caribbean. Through learning traditional building methods as well as sustainable contemporary technologies, students contribute to the maintenance and development of communities and physical spaces. In this way, there are both quantitative and qualitative principles that work toward the vision of community growth. The correlation between architecture and culture is clear. This thesis uses this concept as the backbone for the 
programmatic development of the design project Littlefield, Detroit.

\section{Program Development}

This section describes the economic-industrial and spatial conditions of the chosen site. Most importantly, aspects of the program are considered in order to maintain and further develop the strength of the community. The resiliency of places is not just determined by jobs, but by networks of people: their social and cultural connections and their dignity. The development of the program for this project relies on both exhibited economic trends and the growth of the creative class.

\section{Economic Considerations}

Retooling for Growth is a collection of writings published in 2008 that encompasses strategies to revitalize industrial areas in America. In this study, workforce skills development is a key factor in rejuvenating industrial cities. In their piece about occupational clusters and opportunity, Markusen and Schrock advocate a labour-centered approach to economic development. With a focus on integrating workforce development with industrial growth, Luria and Rogers present an argument for the growth of manufacturing as key to economic development. Reversion to an industrial economy may seem impossible for a city like Detroit; however, this project suggests that existing networks could be employed in new ways. Adaptability is a strong indicator for success of businesses, and creative people are often at the centre of the conversation. According to other research, entrepreneurship is growing.

Elaine Pofeldt documents the trend of self-starters in an article in Forbes magazine. As of 2013, 69\% of new businesses in the United States start at home, and 59\% of established businesses are home based. The data also shows that people of every generation are taking 
chances to start their own businesses: 15 to $20 \%$ of the workforce, spanning all age groups, is engaged in running a startup or a more established business (Pofeldt, 2013). Because of this, the educational program of this project includes entrepreneurship as a basic skill and overarching goal.

\section{Creative Programming}

Richard Florida stated "the image of the factory as an arena for rote physical labour alone has always been wrong." He goes on to say that these workers use creative ability to improve processes and products (2012, p. 34).
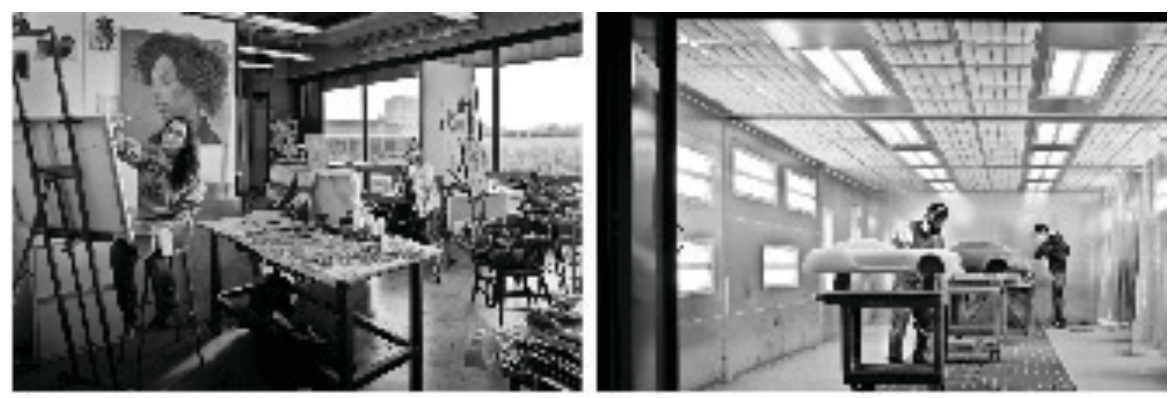

Figure 4 - examples of craft programs

To diversify and densify the activity in the neighbourhood, this thesis project draws on the idea of collaborative creative spaces. An article on the popular architecture website Arch Daily asks if architecture can make us more creative in a piece about academic environments by Jonathan C. Molloy. The iconic example of a school building that did this unintentionally was MIT Building 20, which was the hub of creativity caused by a lack of space that caused proximity between conventionally disparate realms of study. Arthur Koestler wrote on the philosophy of creativity in his book, The Act of Creation. In it, he argues that bisociation between disciplines merges frameworks of thought and reality, to incite new relationships and discovery (1969). The idea that bisociation between types of thought can be a spark for creativity is logical, 
and the type of art and design disciplines prominent in Detroit could benefit from a place where entrepreneurial, collaborative work is nurtured.

Problem solving can be taught, but curiosity and creativity are intrinsic to children. Sir Ken Robinson spoke about how schools kill creativity on the TED stage. In the talk, he touches on the development of public education and how it was designed for the industrial age. The inflation of University education, which has been demonstrated by the decreasing value of degrees, demonstrates the need for change to prepare young people for the world today (Robinson, 2014). This project is programmed to reconcile the disconnection between education and industry, with a focus on creative spaces that are both historically sensitive and equipped with modern technologies.

\section{Creative Spaces}

What are the aspects of space that inspire productivity, comfort, creation and positivity? Education architecture lends itself to spaces inviting play and more explicit relationships to the outdoors. Wider, programmed hallways with casual seating areas, art boards and places to read and write are commonplace in well-known post-secondary institutions.

In 2008 Gensler published an architectural Workplace Study. The findings say that top performing companies design workplaces to support all four of the "work modes" they have defined. The best designs reflect spatial qualities that have greater likelihood of allowing for each of the following modes: focused work, collaboration, learning and socialization. The study attempts to establish measures of performance that would make a difference in the growing knowledge economy: focusing on the power of people and place to drive profit (Gensler Design, 2008). Based on the work modes, it can be presumed that higher levels of accessibility 
allow for collaboration and socialization, and that closer spaces with more privacy and personal furniture and storage systems predispose focused work. These considerations will be taken into account in the design of the project.

\section{The Creative Community Project}

The Creative Community is a response to the problem prevalent in post-industrial cities like Detroit. Detroit is a city with a particularly strong building stock, but without the economy and social capital to inhabit and maintain it. Another problem is the sprawl of the city, which results in low density that compounds the presence of blight. This thesis engages with a pervasive contemporary problem: the disappearance of industry from cities that were historically manufacturing centers. A fading economy results in the decay of architecture whose bones remain striking and immediate; how can these be muscled and fleshed to face the future of industry, and, more sensitively, how can citizens become engaged with them to reinforce communities and reestablish networks of urban density?

The project stems from a real place; a stone cutting factory owner has requested architectural ideas to better his community as an investment in his business. The site is located on a residential and industrial edge. Close to highways and situated midway between downtown and the suburbs, the site is uniquely positioned to provide housing and work environments that should appeal to entrepreneurs and students. This thesis project proposes that by locating living, working and education facilities together in a creative environment, a diverse and vibrant community would hopefully emerge. The mix of programmatic uses ranges from private to public: residences, workspaces, classrooms, a showroom-gallery and a cafeteria form the program of the new building. Historic tools taken from the existing factory's collection will form a dialogue with the contemporary products in the showroom gallery. Student-oriented business 
incubator units will provide flexible work zones for aspiring designers, artists and craftspeople. Symbiotic to this will be the education wing, forming the largest section of the new building. A prototyping centre, offices for the stone business, and a showroom will act as the spaces that go between the existing factory and new school. This will be where factory and student users can form collaborative relationships.

In this instance the project is rooted in an existing traditional manufacturing company. In other urban areas, it could be implemented as a standalone project but ideally it would be associated with buildings that have fallen into disuse. The purpose of the design is to construct a catalyst - a microclimate of the most positive aspects the city. The project seeks a balance between traditional and contemporary ideas of building reuse, the value of apprenticeship, community versus individuality, and craft versus assembly, with the philosophy that through design, the Creative Community Project can help foster a safe, productive and vibrant community.

\section{Case Studies}

For the Creative Community Project to become a successful architectural intervention, I began by researching successful examples of adaptive reuse. More specifically, the buildings chosen demonstrate qualities of adaptation through the use of contemporary building technologies, often in areas of cities where industry has changed much like it has in Detroit. Precedent studies were chosen if they had a uniquely successful or inspiring ability to maintain old structures' integrity and architectural value, while adding architectural elements and programs that extend the building's life cycle. The analysis of this research will attempt to discover what makes these projects successful, and discover what qualities of space will best function for a creative community building. 


\section{Pittsburgh}

Pittsburgh is a rust-belt city that has struggled to overcome the challenges of a lost industry. Formerly a steel city, industries such as education, tourism, healthcare and information technology have replaced steel as the economic pillars of the city. The city is said to have gone through two so-called renaissances, which are commented on in a journal article on urban shrinkage by Thorsten Wiechmann and Karina Pallagst (2012). The first took place after the Second World War, and involved the demolition of disused industrial structures to be replaced by modern towers. The second was lighter handed, valuing historic buildings and focusing on neighbourhood level redevelopment. Finally in the 1980's, the economic crisis pushed towards the diversification of the city's economic structure (Wiechmann \& Pallagst, 2012). Richard Florida, who resided in Pittsburgh for nearly 20 years, noted the strength of ethnic neighbourhoods and community pride as a factor that helped keep the city from collapsing with its steel and heavy industry (Florida, 2012).

\section{Bernard Tschumi's FRESNOY}

The Fresnoy is a combination of old and new structures that interact with each other. An encompassing roof structure encloses and unifies the project. The roof binds the project spatially and in plan. This project includes areas that are unrelated to one another, except spatially. The functions of the buildings are separate but entwined by their proximity and the overarching goal of the project - to a unified visual composition and to provide more program space.

\section{The Ljubljana City Museum by OFIS Architects}

This project involved the design of a series of curving ramps that stitch together the 
fabric of the original palace structures. Contemporary glazed walls enclose a previously open courtyard space. The material-less quality of the addition allows the preexisting building and context to maintain importance and visibility. The roof of the extension appears to have been lifted from the ground to create more interior space within the partially enclosed courtyard. The result is a well-balanced, functional project that has increased area for added program.

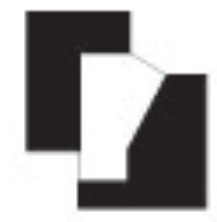

Figure 5 - plan diagram of the Ljubljana City Museum and addition

\section{Architecture Firm's Office and Exhibition Space in Shanghai}

In this project, the damaged stucco covering original brick walls was removed to reveal the structure and materiality of the fabric warehouse. The existing building consisted of three rectilinear structures. An articulated concrete block wall was designed to encase and unify the complex aesthetically, while controlling light penetration and views. Within the open warehouse space, a conference room was constructed as a building within a building - a room within a larger room. The designers chose to remove the roof from the middle of the three parallel units to create a central courtyard space. The separation between the new and old structures successfully defines adjacent spaces while maintaining the users' understanding of the structures as whole entities that are connected, but engaged in dialogue. 

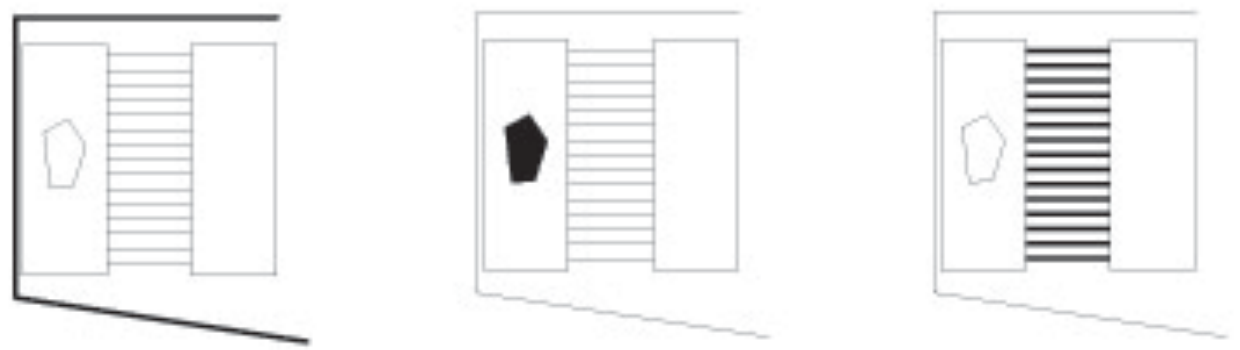

Figure 6 - plan diagram of enveloping, building within building and peeling

\section{METU MODSIM by Yazgan Design Architecture}

This example is a building for modeling and simulation at a technical university in Turkey. In plan, the layers of program are nested within each other. The centre is an open atrium, surrounded by a circulation corridor, offices, mechanical spaces and exterior cladding.

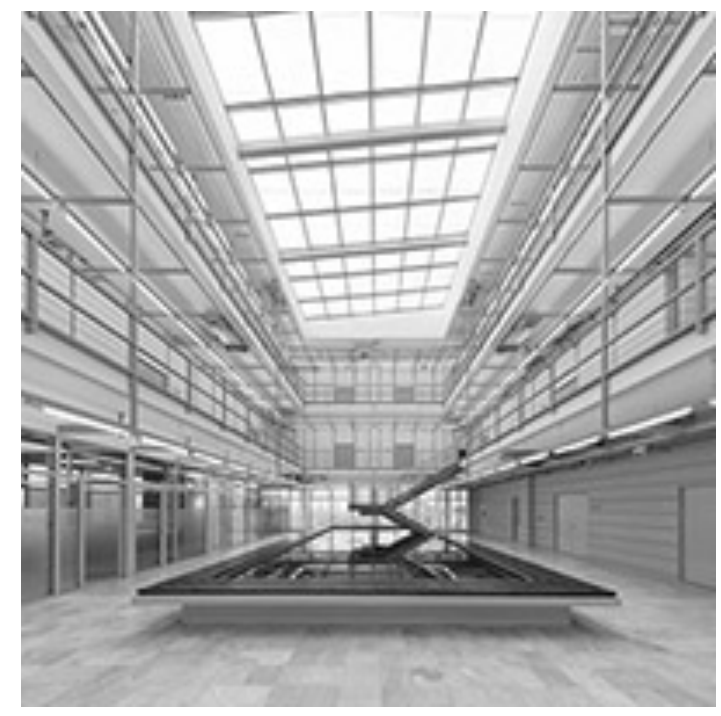

Figure 7 - interior courtyard

\section{Business Incubator Training Centre by $\mathrm{H} 2 \mathrm{O}$ Architects}

This example is a reuse building where the architects implemented an internal street and square to encourage interaction between entrepreneurs that are working or training in the centre. This creates a zone for informal meetings and discussion. 


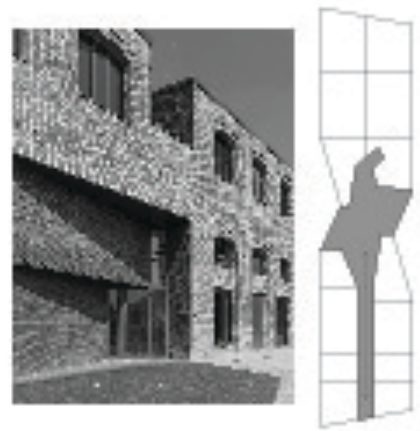

Figure 8 - entry to internal street

\section{Trade School in Switzerland}

Modern architecture and vocational schools as a typology share their timeline in history. In 1940, Hans Brechbuhler designed one in Berne, Switzerland. There, the philosophy of handson training was well developed due to the school's century long history. The first component of this two building complex is a large multistory structure raised on plinths, with a ground level terrace adjacent to the cafeteria, with workshops in the floors above. The second building is a one-story factory type structure, which holds the heavy industrial programs.

\section{Extension Bullingstrasse Vocational School by EM2N}

The key concept for the extension at Hardau Schools in Zurich was to connect and rationalize a difficult site, while providing additional program space for the vocational school. Completed in 2005, the building ties together several existing facilities and creates an urban park and throughway available for use by neighbouring residents. The architects used the existing building's structural characteristics, "cloning" and "mutating" them to rationalize the building and the site. In contrast to the perfectionism of the "Swiss box" architecture popularly based on the high standards of the skilled building trades of the country, EM2N are less focused on the 
object, and more concerned about the connections across the site and its urban quality.

\section{Schulhaus Bruggerstrasse by Burkard Meyer}

This project exists in an industrial zone, translating an old labour welfare building into a component of the new vocational school. In this project, a new building type is explored with a classical layout. This is an example of a school that can host a multitude of programs side-byside.

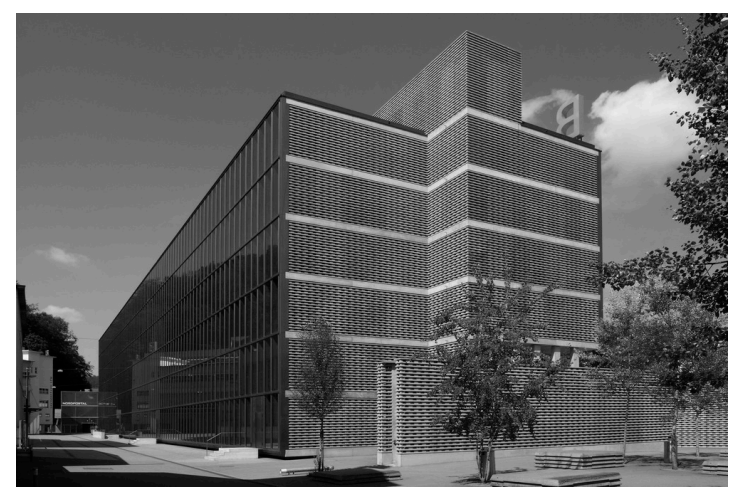

Figure 9 - Schulhaus Bruggerstrasse 


\section{PART 3 | DESIGN}

The design considerations illustrated below begin with a demonstration and analysis of the site. The design of the building is shown next, taking into account the research and the case studies from Part 2. The three key concepts of this thesis project that will be explored in this section are:

\section{Building a creative community \\ 2. The dichotomy of new and old \\ 3. The relationship between education and the economy}

The architectural components that stem from these qualities have been determined by the research and case studies; the main components are the two volumes that intersect the old and the new building, which forms the design parti.

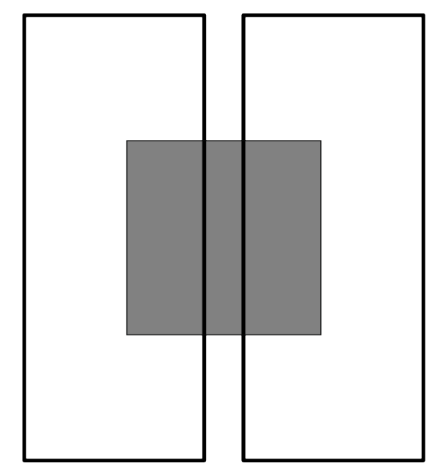

Figure 10 - parti of the new and old being bridged by a volume

The design objectives, determined by the qualities of the site and the requirements of the client, are quantitative - concerning physical security, privacy and historical preservation - and qualitative - focusing on downstream, immaterial qualities like creativity and economic wealth. 
The culmination of these concepts on the site in question resulted in the exploration of nested spaces; with forward thinking programming that encourages creativity and communal work between the users of the site.

\section{Design Rationale}

The definition of the thesis project is framed from three vantage points. Any architectural response is guided by a multitude of influences and limiting factors that incite problem solving. Like a real-world building project, the site is predefined. The project therefore grows from the existing context from a small scale, while being representative of trends and patterns on the global scale.

The architectural responses in light of the following three concerns are listed below.

1. The client/ existing factory

- preservation and physical improvements

- exploring the history of the site

2. Site conditions/urban conditions

- edge conditions for a secure site

- urban manufacturing and residential edges

3. Projection of the future economy/catalytic programming

- future manufacturing trends

- creative industry program

The Project attempts to accomplish a number of quantitative and qualitative goals including protection, integration and memory.

Protection. A cohesive, defined project becomes a node of activity. To achieve this, Defensible Space qualities are implemented. Exiting is planned and unambiguous. The site and 
street are visible from the interior. Ownership of the site is clear, and thresholds are created from public to private realms.

Integration/buffering. The inclusion of a number of uses and programs serve as zones of reprieve from the intensive industrial use, and act as more neutral zones. The public is included in programming - with the showroom for Roman Stone Works. The residential area is buffered by commercial/educational and open space.

Memory. The vision of the project is to create an identifying feature for the site, and concretizing the history of the site by maintaining sensitivity to the neighbourhood and the existing building and its internal operations.

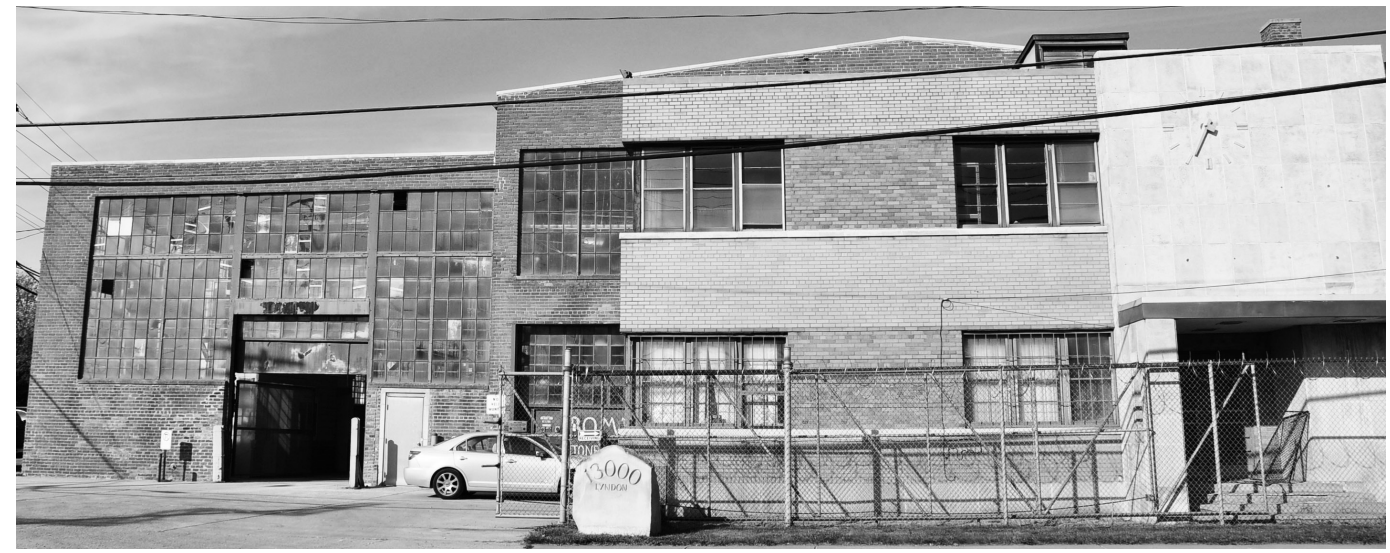

Figure 11 - south elevation of existing factory

\section{Site}

The site is located at the corner of Lyndon Street and Cheyenne Street, in a neighbourhood called Littlefield. Lyndon is an industrial corridor, and Cheyenne is a residential street. The site therefore acts as a buffer between these disparate uses, which, according to the zoning ordinances, do not take place adjacent to each other. It is clear that this is not the case, and the majority of the industrial area does in fact abut residentially zoned blocks. The existing 
program of the site is an industrial stone-cutting factory that processes residential and commercial architectural limestone. Built in 1935 with extensions added in 1937 and 1950, the building was originally a steel-slitting factory. The neighbourhood of Littlefield is a typical example of the overall residential condition in the City of Detroit, with many adjacent vacant houses and empty lots dotting the previously occupied landscape of properties. In a single location where interest in improving the neighbourhood has been shown, incremental changes will be attempted in order to achieve long-term neighbourhood sustainability.

The following demographic and property information describes the neighbourhood of Littlefield, Detroit. It hosts average household incomes between $\$ 20000$ and $\$ 40000$. The unemployment rate is $2 \%$ to $7 \%$. Rent prices range between $\$ 620$ and $\$ 1200$ monthly (Detroit history, 2008). The population density for Littlefield is higher than that of Detroit overall; in Littlefield, there are 7252 residents per square mile and in Detroit there are 5283 residents per square mile.

The 2013 Tax Foreclosure Auction has provided some information regarding which properties are abandoned or being foreclosed, and the price of property in the area for different uses. For example, 12770, 12740, 12700 and 12400 Lyndon Street are commercial and industrial buildings that are listed with minimum bids of between $\$ 10000$ and $\$ 60400$. Approximately fifteen nearby residential lots in the neighbourhood to the west of the site are also being auctioned at very low prices, with minimum bids set at $\$ 500$ (Why Don’t We Own This, 2014). 


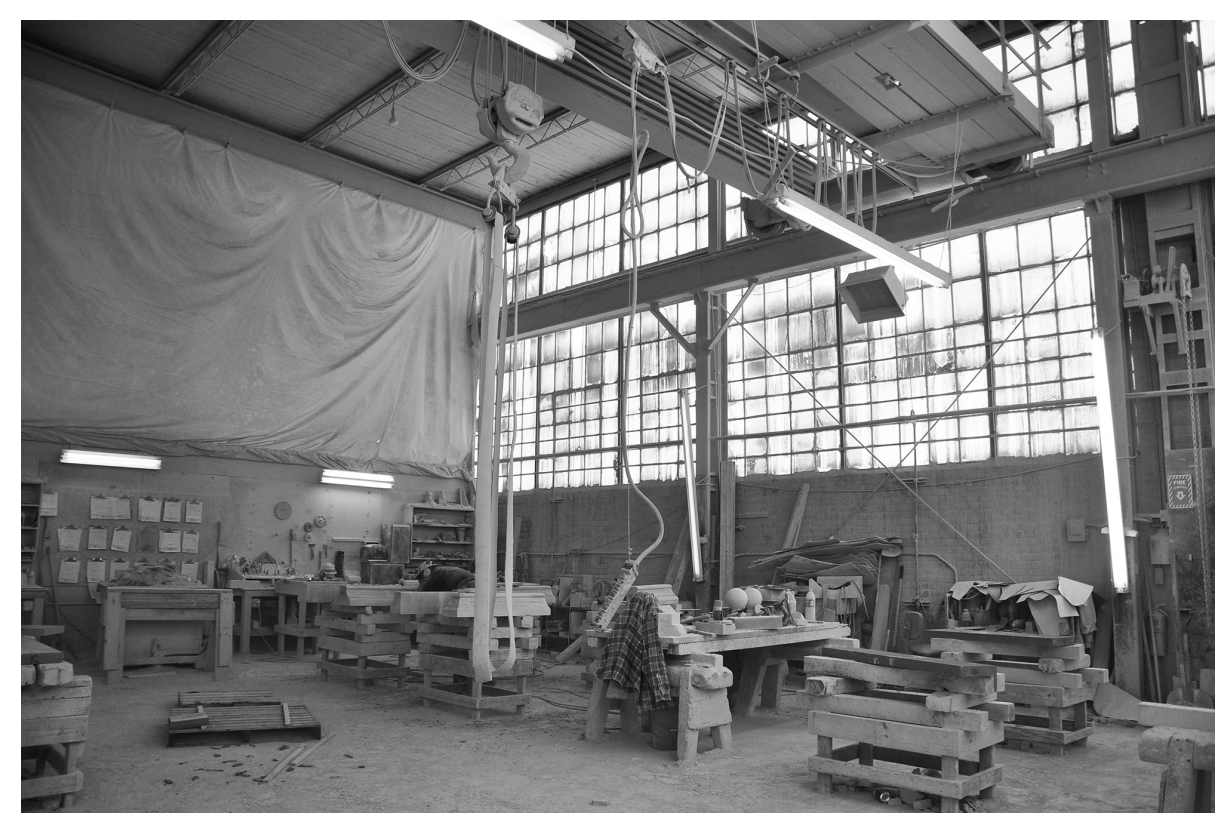

Figure 12 - manual carving area

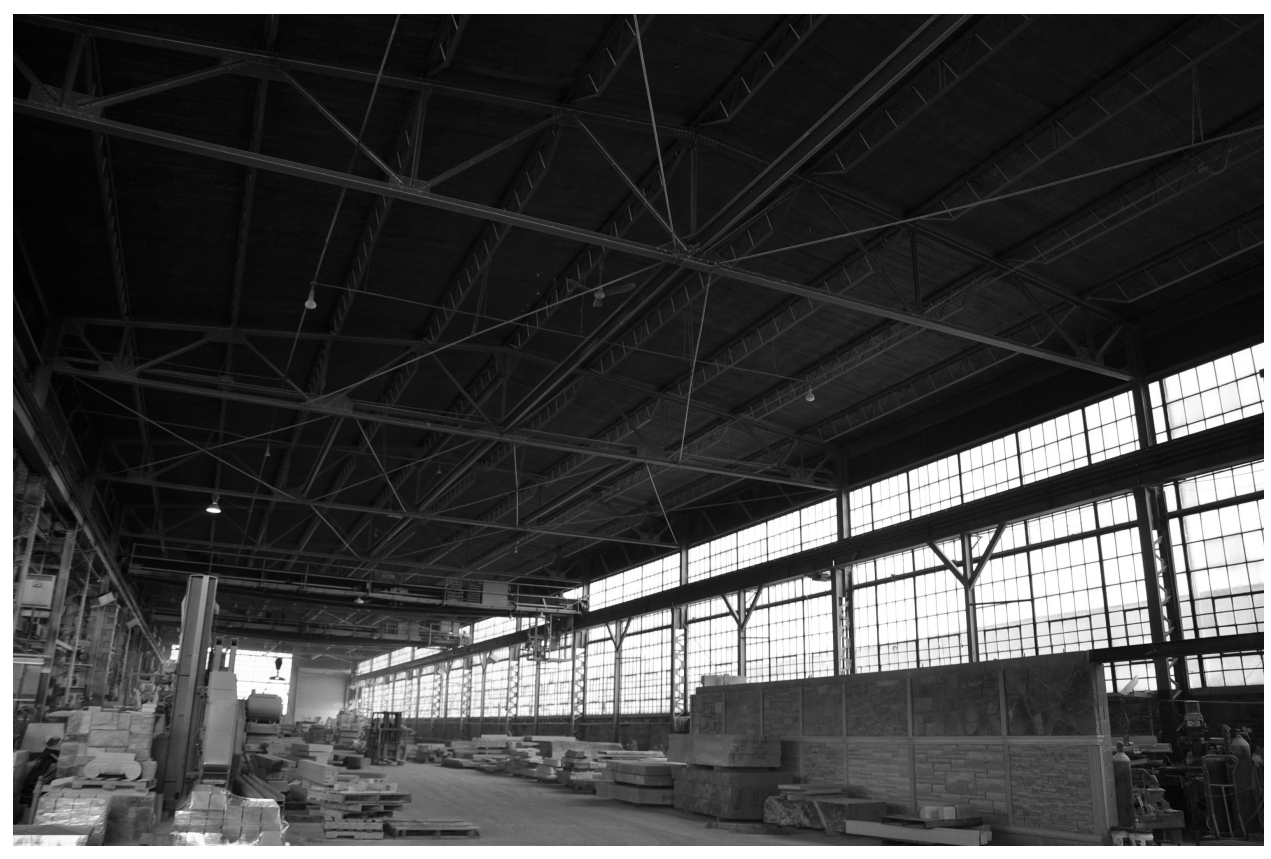

Figure 13 - interior view of the existing factory 


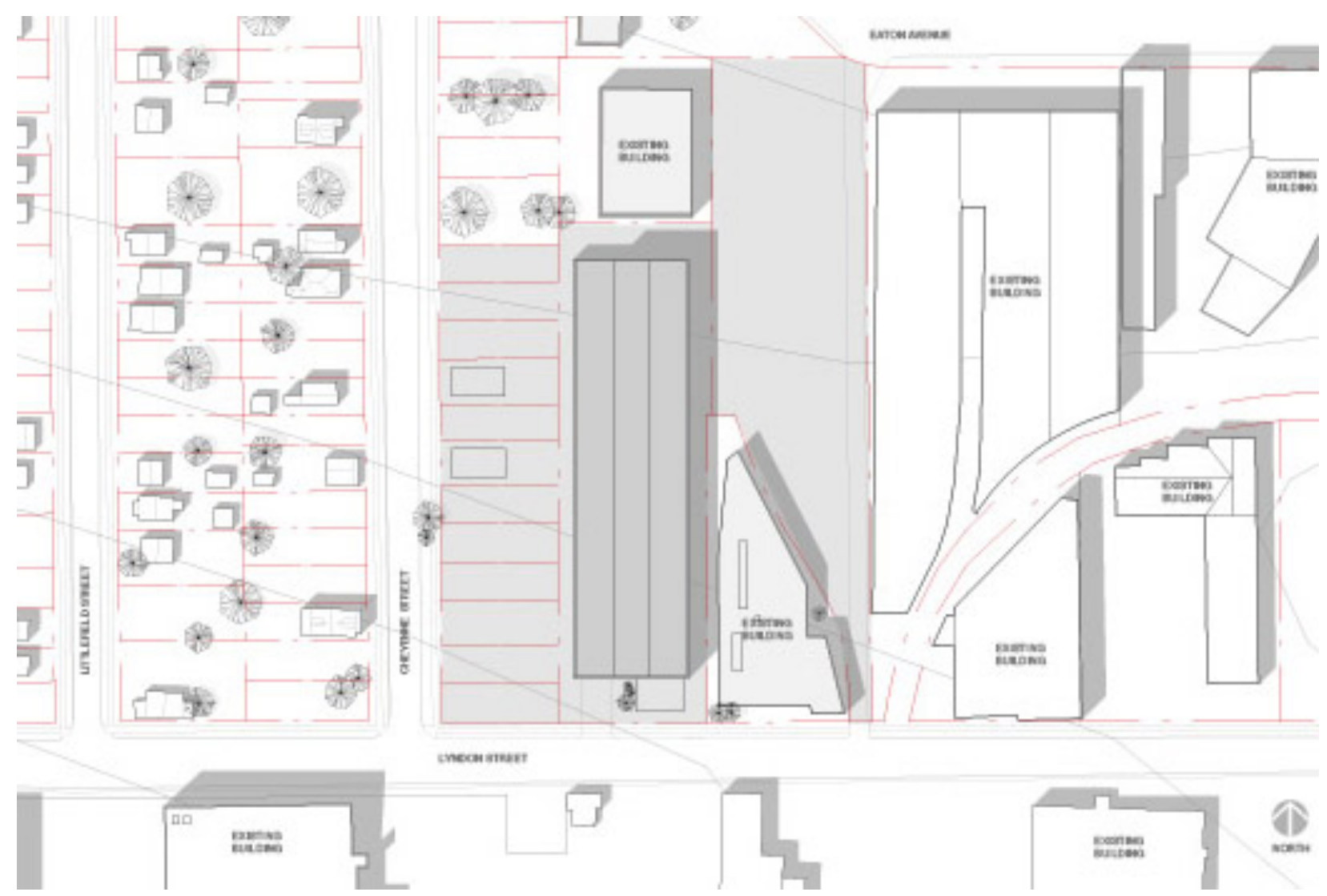

Figure 14 - existing site plan

\section{Client}

Craig Cassel is a business owner based in Detroit, Michigan. From the founding family of stone-cutting company Arriscraft in Cambridge, Ontario, he started his company Roman Stone Works a decade ago. Situating the company in Detroit, Michigan allowed for the business to grow both in Canada and the United States. This "client" provides a unique opportunity for this thesis project to study the contextual aspects of a Detroit factory that was built during the industrial boom and is still in use. He has a successful business in an environment that has proved unstable for multitudes of companies.

This project began because of the growing interest in historic architecture. Adaptive reuse projects are most often are objects of gentrification, where factories become 
condominiums or museums. This project is an exploration of the relationship between industry and neighbourhoods, and the changing nature of the architectural requirements for industry. The project is site specific, but the general range of topics covered, such as blight and vacancy in Rust-Belt places and the architectural consequences of these, is applicable in many cities.

\section{Technical Site Requirements}

The site defined early in the design process is zoned R1 - residential, M4 - intensive industrial and P1 - parking. The existing parking area is not fully in use and encroaches on the residential zone, so this projects will redefine that discrepancy by programming the corner lot to its fullest extent.

The height restriction for the residential area is 35 feet (just under 11 meters) - and 80 feet (just over 24 meters) for the industrial area. There are no setback minimums for the industrial zones but the residential setback is 20 feet from the street and 30 feet from the back property line, with minimum side setbacks of 4 feet from adjacent properties, and a combined 14 feet when taking into account both sides.

\section{Contextual Site Requirements}

Security is a major concern for home and business owners in Detroit. A concern for any building project that is in an area with nearby abandoned buildings is the problem of security in areas because they lack eyes on the street and have a propensity for squatters and looting. The concepts of Defensible Space have been considered, providing guidelines for the applicable planning concerns. These include the orientation of the site and the nature of the entrance area, as well as exiting and the definition of multiple levels of site boundaries.

The first objective of this project is to design for protection. Projecting a cohesive and 
well-defined project onto the site - one that can become a node of activity, does this. Defensible space qualities help to achieve a safe and positive vision for the site. These include the implementation of spaces that automatically project eyes on the street, a feeling of ownership of the space for users and thresholds that define public to private spaces.

Spaces are defined in a hierarchy from public to private. There are different levels of barriers ranging in their ability to filter access. Symbolic ones include: changes in paving, stairs, open gates and planting. Real barriers include walls and doors with checkpoints. The showroom is to be visible from the factory and will incorporate a reception area. For the school entrance, the administration office will be open visually into the lobby.

For exiting, an important consideration is the location and visibility of fire exits. Although they can be unsightly, they should not be hidden from plain view because it could become an exit strategy for criminal activity (Newman, 1973). In this project, exits have been planned to anchor the north and south ends of the school. The idea of the panopticon has also been considered because surveillance - even if it is just perceived surveillance - is an important tool to maintain security. Sightlines within the building and towards the street provide this.

\section{Program Elements}

The implementation of new program elements is the means to structure the exploration of combining new and old industrially programmed architecture, while addressing real time site concerns. The city of Detroit is so defined by its industrial and residential growth. The side-byside stretch of suburban and industrial growth results in a problematic condition, where a lack of density compounds the presence of blight.

There are two current manufacturing and cultural trends that guided this project: the return to craft and the prevalence of digital design and fabrication as a niche industry. Some 
examples of these trends are Detroit watch-making company Shinola, and the success of the company Roman Stone Works. In digitally based craft manufacturing, there are several interesting businesses in the US and Europe - Shapeways and i.materialise. These companies source designs from people everywhere, and build prototypes, models and objects they can then sell. There is a cultural connection between the creative class and the increasing value placed in well designed and crafted items. It is something that is taken advantage of in marketing; for example, Ball Heritage Collection mason jars of the classic blue have been released in limited numbers for the company's 100-year anniversary. Interest in Americana is solidifying and marketing the culture of the United States; the relatively short history of the country results in a dichotomy between the positive, and the often-referenced negative connotations of the United States of America.

\section{The Designer and the Craftsman}

The educational component of the program has been conceived as a means for this design thesis to participate in a dialogue with the site. The dichotomy between pre-and-postindustrialization is addressed on the site, in the architecturally interconnected school and factory building. The city already has a strong presence of post-secondary education. This project explores the interconnectedness of creativity and industry, and how hands-on training that apprenticeship offers is not only valid in today's economy, but indispensable.

The word architecture has roots in the Greek language, and means chief builder. Vitruvius was the first to write about the discipline in detail. Giorgio Vasari published the first edition of his history of Italian artists called The Lives of the Most Excellent Painters, Sculptors and Architects. In it, he identified the discipline. Palladio was one of the first Architects as we see them practice today. He designed palaces for clients, who were engaged in the type of 
contractual relationship we associate with practice today. Education changed within the field once it was defined as a discipline distinct from other crafts. Pupilage and apprenticeship have shifted towards the more commercialized and formalized University education.

In the existing factory, a large portion of the building surface area is glazed, and the workspace receives an abundance of natural light during the day. Digital and manual methods of stone cutting are employed. The business is also expanding to include autoclaved aerated concrete, which is an alternative that is light, fireproof and has a smaller carbon footprint than traditional concrete. The added program in the expanded site includes educational, residential and commercial zones. Two houses in the residentially zoned area are being removed and replaced by four townhouse units for student rental. A showroom and office spaces for both Roman Stone Works and the school are being added as well.

The educational component can feed into the industrial - because computer programs already systemize the limestone cutting, the student designers can see their work in progress by modeling and prototyping. The aerated concrete aspect of the company can be taught, designed

and tested. Traditional hand carving occurs adjacent to digital fabrication design and research in the prototyping centre. Spaces are multipurpose and varied, from large open spaces that can be rented for holding events to well-defined computer lab, classroom and office spaces. These rooms could also be used for continuing education programs. The lecture hall and cafeteria could also be used to host and cater to events planned within the community.

\section{Site Analysis}

Materiality and geometry. The existing factory building is a glass box defined on the exterior by red brick and on the interior with steel trusses and beams. These three defining features are being maintained and counterpointed with the development of the extension. The 
dimensional geometry of the existing building will be repeated and used as an organizing tool to define the site in plan and elevation, and the interior spaces.

Scale. The existing factory building is very large at approximately 3600 square metres, and is at odds with the small scale of the adjacent neighbourhood. The land surrounding the building creates a fabric defined by open space. Much of the open space is inaccessible, due to fencing, and remains inactive. The site will be opened up towards the residential street on the west, but secured on the industrial side to the east. The addition nearly doubles the area of the project, inhabiting prior vacant lots and reestablishing parking and materials storage for more streamlined operations.

Public versus private. Property lines define layers from west to east and north to south and help determine the organization of the programming. The south and the west facades, and the southwest corner of the site are the most visible from the street and most accessible to the public. Complexity was added by determining relationships between spaces and uses above and below. The differentiation between visual relationships and physical proximal relationships is also read in the material language and levels of transparency. The physical relationship between the old and the new is created by peeling away a portion of the exterior skin of the west bay which is the smaller of the two - and appropriating two parts of this section as a buffer zone; these volumes bridge from the school to the factory. 


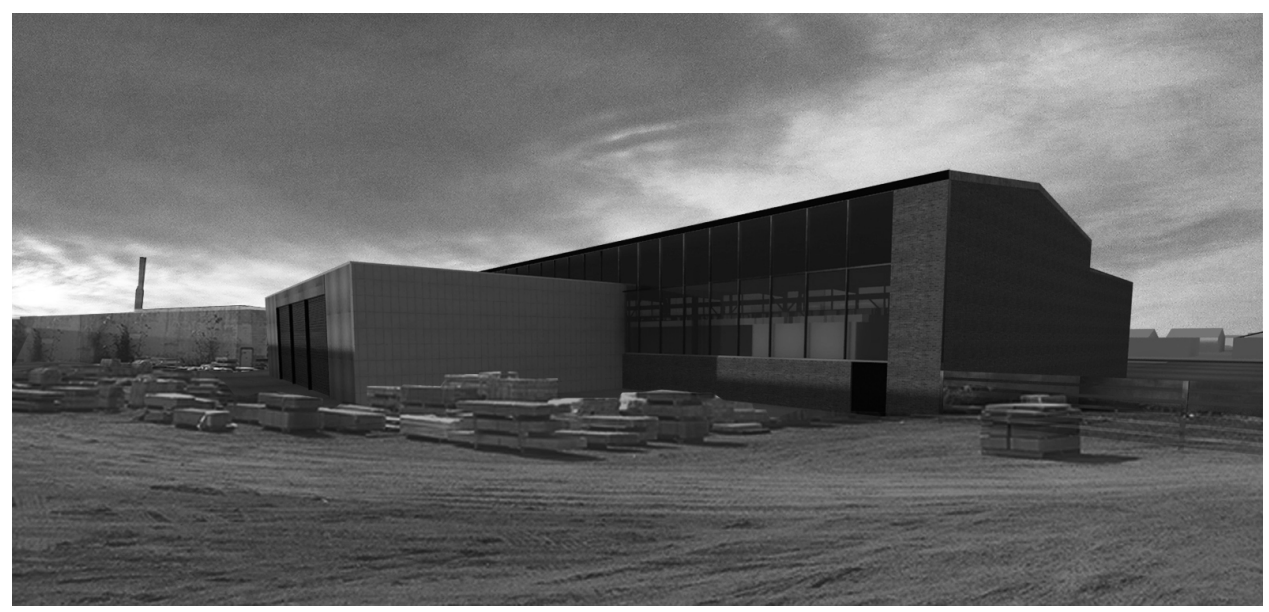

Figure 15 - stone yard and receiving entrance

Process and procession. Factories are designed based on processes and the movement of goods and workers. The existing factory already has processes entrenched and other requirements that began to determine the logic of the site. The limestone business involves cutting and carving very large quantities and dimensions of product. This process creates a large amount of dust that is important to control. The water used in the process also holds sediment that can be safely dried on site and used in concrete products; at this point this does not happen - the water is simply stored and disposed of on a regular basis. The architectural divisions of spaces need to be rethought in order to efficiently ventilate and enclose the areas that are highly active. New processes will be added to the site with new program. The building is a machine of industrialization; the assembly process is linear and top down in a traditional factory.

Design processes are iterative and bottom up. Today's creative economy requires a more open, communicative environment. The factory becomes a teaching ground while maintaining its ability to perform at an industrial scale.

A number of actions around the existing building will have to take place. Some of the following are strategies used commonly in adaptive reuse projects. They are strategies that help 
designers navigate between new and old; mimicking form and void, highlighting differences, shadowing, and revealing are all examples seen in the case studies. This design uses deletion and addition and building within a building to define space. Looking at the floor plan, the two rectangular spaces are the bridging volumes that span between the old and new (see figure 21). On the northeast end of the structure, a receiving bay was added to accommodate the delivery of raw materials (figure 15).

\section{Conceptual Organization}

Ordering concepts of the interior organization are based on connecting the program elements to the required adjacencies, while maintaining processes within the factory and implementing new program towards the community.

\section{Defining the Site Extents}

The existing building is a unit from which the site will be extended. The intersection the site abuts will act as the southwest extent of the site. The property lines define the site, and added to this site are six residential properties, four of which are currently vacant.

\section{Superimposing Ordering Systems}

The initial site organization was determined by the need to mediate between the existing residential and industrial zones that are adjacent to each other, the boundary of which exists directly on the site at 13000 Lyndon. The buffering of the two zones - industrial and residential - is reinforced by the bridging of old and new.

\section{Material Systemization}

The materiality choices were dependant on the structure and were determined by the existing building, the requirements for its adaptations, and the scale and program requirements of the addition. 


\section{Connecting Element}

The site encompasses uses that are at odds - the residential and the intensive industrial uses are adjacent. This project remediates the site by including uses that are symbiotic - the education and the manufacturing of new and traditional materials, and the community resources that will be available.

The site is ordered linearly along the axis of Lyndon Street, which is on the $1 / 2$ mile grid of Detroit at $4 \frac{1}{2}$ miles, and Cheyenne Street. Lyndon is naturally the public access street as a manufacturing corridor and Cheyenne is more private as a residential street in the neighbourhood of Littlefield. The first planning step for the site is to determine the placement of added program. The three main goals for the site are residential buffering, increasing the commercial activity of the area and securing the site from the likelihood of criminal activity. These have been situated based on the existing buildings being maintained, streamlined and updated. Because the process is bottom-up, and site and business specific, the existing occupants' ability to maintain operations takes priority.

Ordering systems in the form of building grids are layered based on the existing buildings. The dimension of the grid is related to the interior structure of the existing factory and helps determine the structure of the new project. 


\section{Final Design | The Creative Community Project}

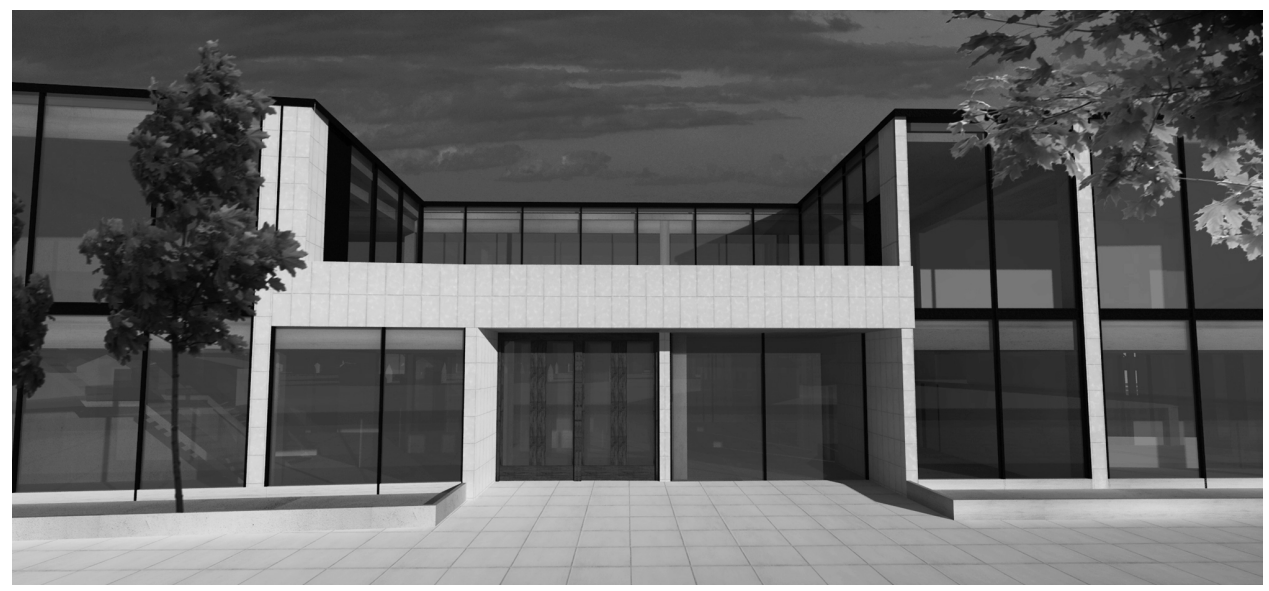

Figure 16 - front entry of the school

\section{Integration/Mediation}

This design is a mediator. It acts to differentiate from and connect to the existing factory. The community is connected to the business, through the articulation of public and semi-private zones carefully placed throughout the site. The object of the design is to integrate and mediate the hostile aspects of the site. The organization of the site was dealt with in a way that orients the school to the neighbourhood, and puts into place planning measures for security. The main entrance to the Roman Stone Works showroom is at the south end of the building. Adjacent to this pedestrian entrance is a vehicular entrance where customers can drive directly up to the factory to pick up limestone products for residential or commercial use. The main school entry is on the west side, adjacent to the neighbourhood street called Cheyenne. This provides student and administrative users a semi-private entry, where residents of the school and students arriving by car are provided access equally. Factory workers enter the site from the south, at the gate on Lyndon Street that also provides access for deliveries by truck. 


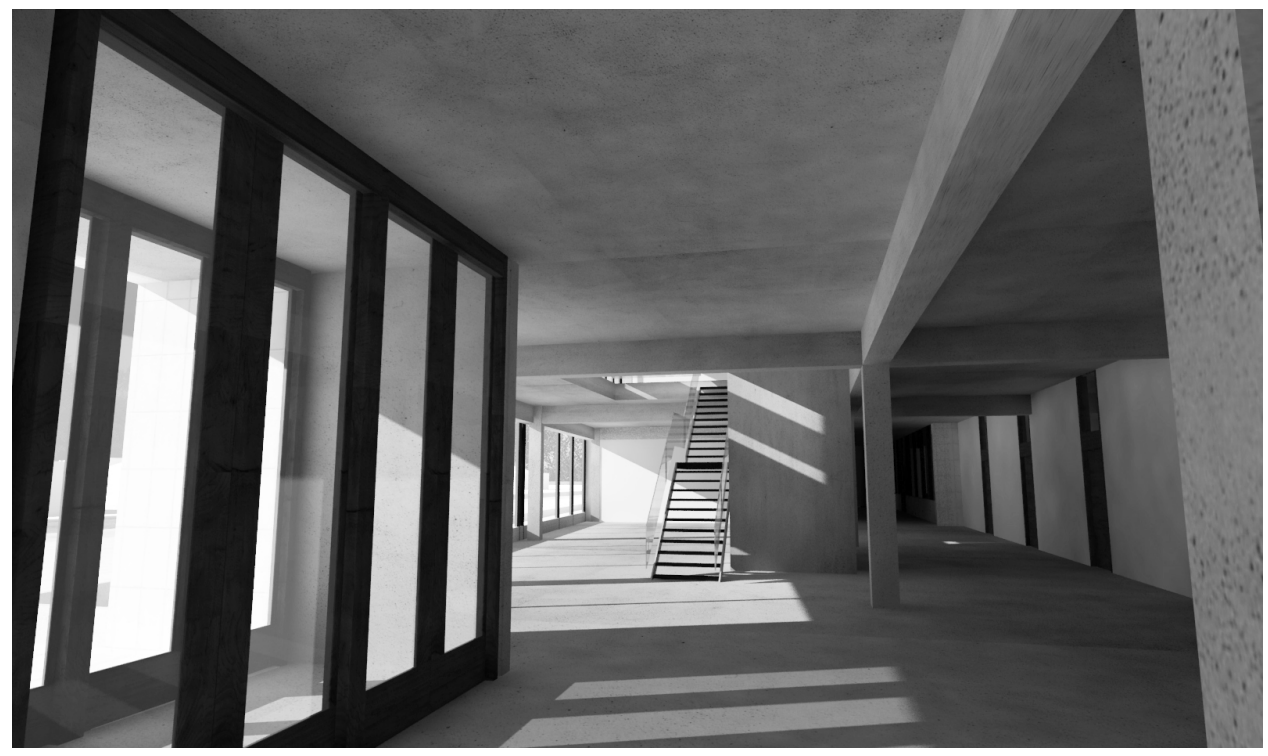

Figure 17 - interior of school lobby

\section{Formal Concept and Materiality}

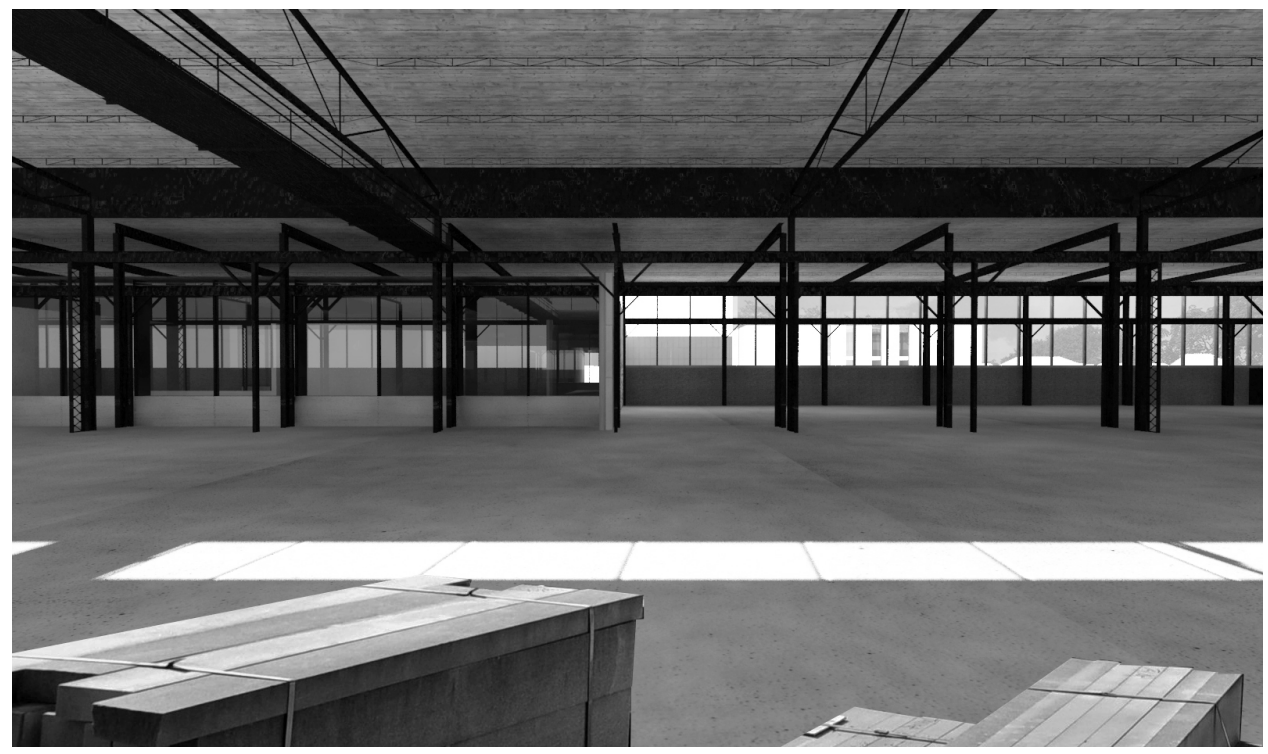

Figure 18 - factory floor view of school volumes

The site orientation is such that the rough quarry yard is to the north and east of the factory, and finished stone façade and paving products are showcased in the extension to the west. The façade is made up of alternating limestone facades and glazing. The limestone is used 
in both quarry face and polished styles. On the interior, light cedar is used on ceilings in common areas - mimicking the ceiling of the existing factory - and for furniture. The majority of the program areas are on a ground level floor, with an additional lecture hall space and cafeteria on the second floor. A stairway in the main entrance accesses the upper floor (figure 27). The large lecture hall is open concept and can be used as a multipurpose gallery and presentation space (figure 25).
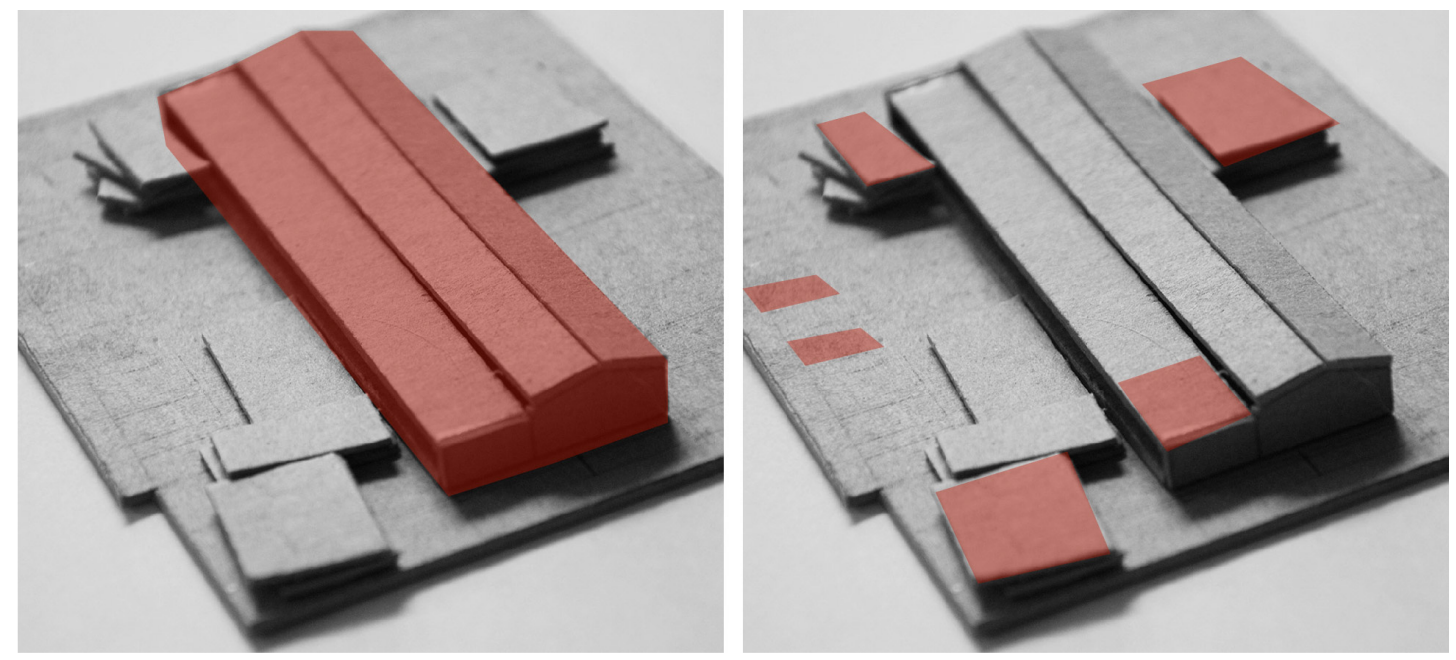

Figure 19 - sketch model of existing building and initial proposed extension

\section{Lighting Concept}

The courtyard between the new and the old building acts as a light well, allowing natural light to be accessed throughout the interior spaces of both. The main floor classroom and computer lab are adjacent to the exterior wall, providing daylight and views. To allow for different work modes including collaborative and personal work, different spaces implement various lighting qualities. Social areas are lit with natural and artificial light. Individual workspaces have personal lighting controls so work can take place throughout the day, and allow for both computer and book-oriented learning. Below, the central volume in the section 
demonstrates the individual office spaces as well as a printing room and two meeting rooms.
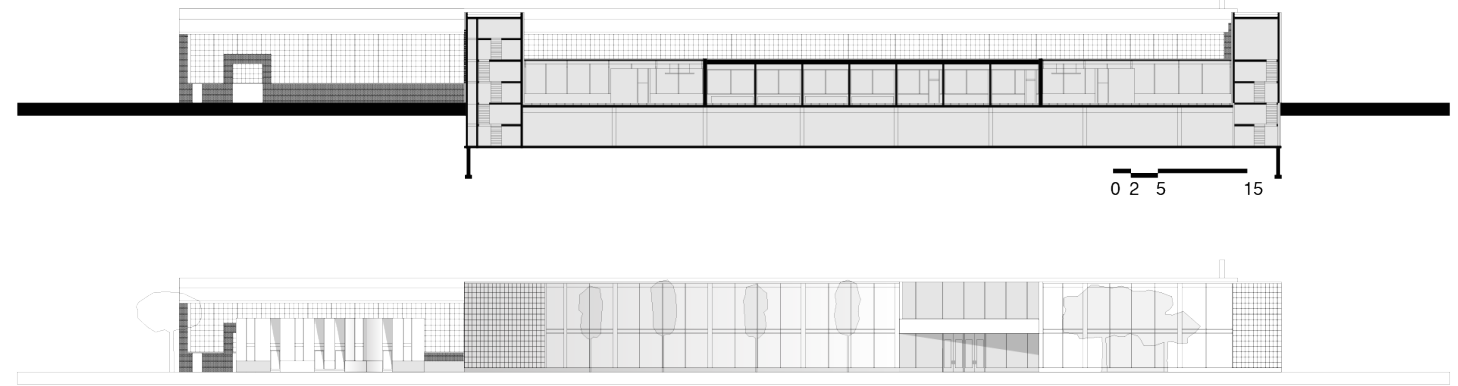

Figure 20 - Section D and west elevation

\section{Landscape}

Hard and soft landscapes are integrated to perform as parking and leisure areas for staff and students. The landscape is articulated with square limestone tiles larger than those on the elevation of the school. Landscape is the lowest level of spatial definition but serves to reinforce the procession and security of the site. Using defensible space concepts of ground surface changes, perceived and real thresholds are created with the angled building face and the planters, which define the path. Another defensible space consideration is the visibility to and from the lobby, which faces the street parking.

The extent of exterior space for this project is limited by the nature of security. The site is enclosed with fencing on the south, east and north extents, but open on the neighbourhood facing west extent. On the east side of the existing building, open space exists that will remain open for the purposes of storing raw materials - the rough quarry - and the creation of a silting pond. There is a laneway bordering the quarry, within the extent of the site. Delivery trucks with raw stone enter on the south of the site from Lyndon Street and exit again to the north on Eaton Avenue. On the second floor, an exterior courtyard is accessed adjacent to the cafeteria. 


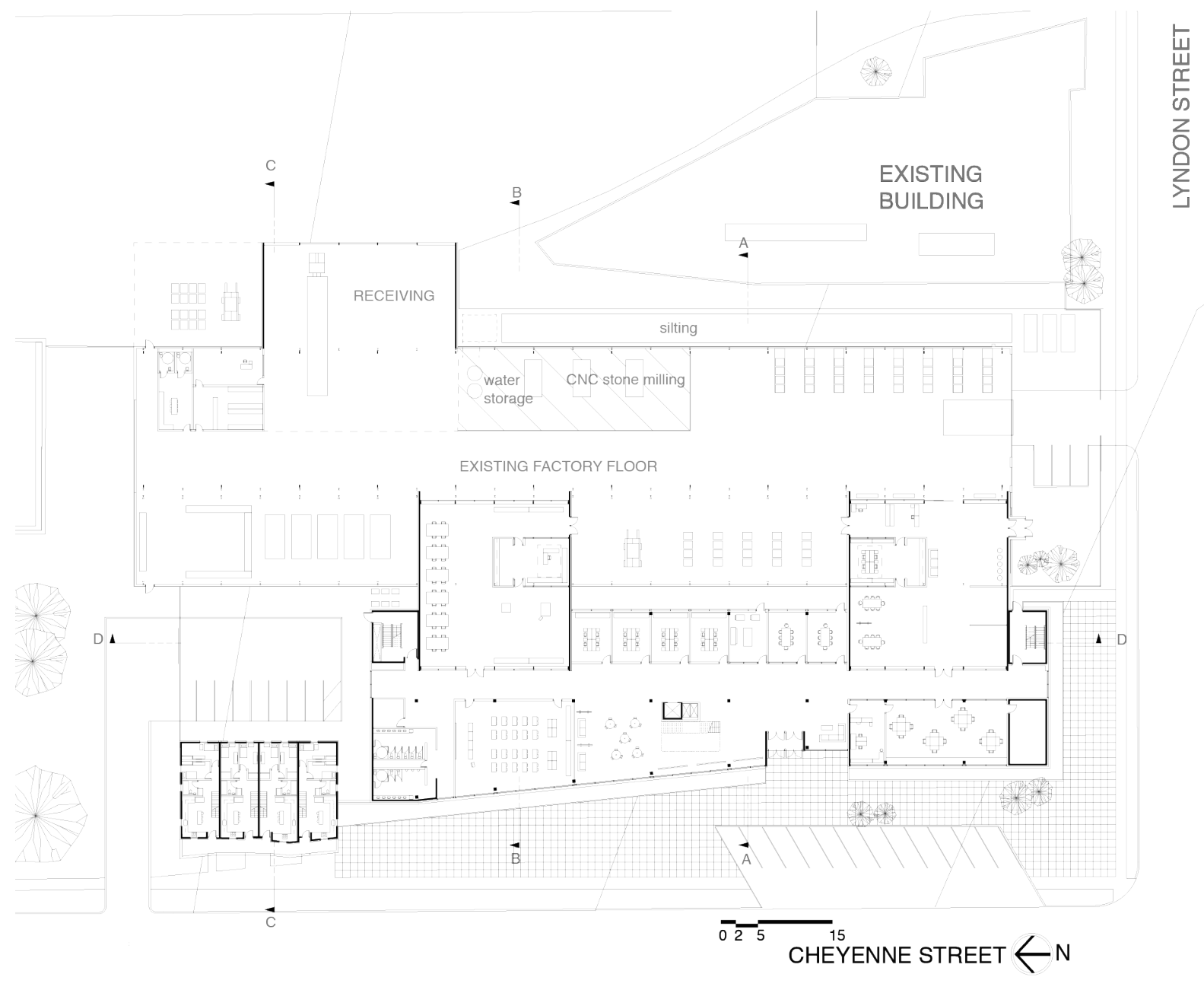

Figure 21 - Floor 1 plan 


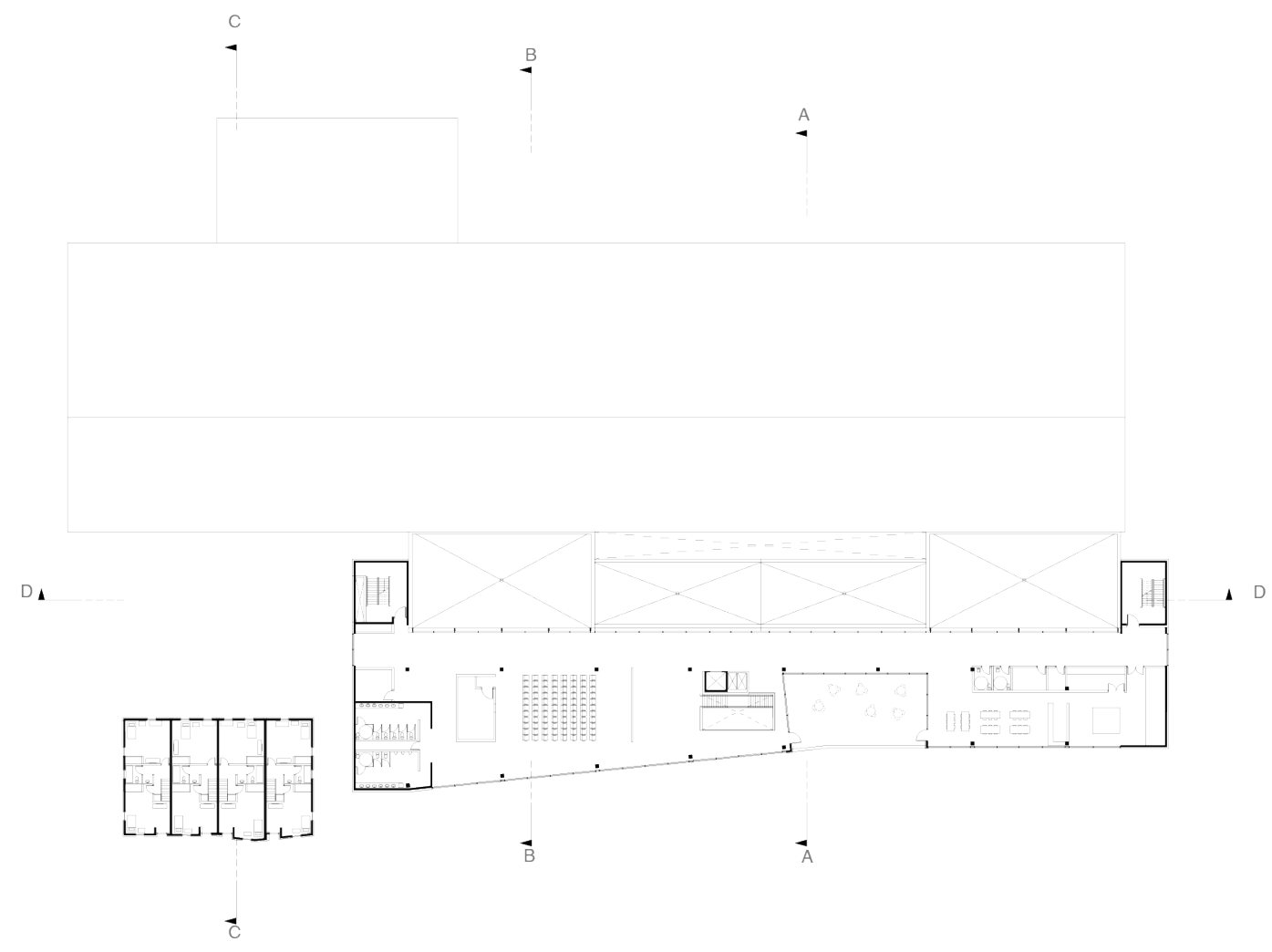

Figure 22 - Floor 2 plan

\section{Memory}

The existing factory building is opened up on the west side in two locations. The first is the entrance for the showroom. The second is the prototyping centre, near the manual stonecarving area and where students can take part in an apprentice-mentor program. The addition of the school is separated from the existing factory between these two intersecting volumes by a long, narrow courtyard that acts as a light well for both structures. The showroom is connected to the new Roman Stone Works offices, taking the place of the removed office on the south 
elevation of the factory. The removal of this office allows for the factory processes to become more streamlined, moving from the receiving area at the north of the site, through processing and to deliveries at the south. The historic tools and stone objects collected by the owner of the factory demonstrate the longevity of the industry he takes part in. These are displayed throughout the site: in the showroom, in the school and outside. The company has in its possession numerous historic machines and tools, including some from the era of the First World War - and some from earlier - that were used as early as the 19th century. The most impressive is the lathe that sits in 13000 Lyndon St - it was used to build the columns of the portico of the White House. The element of historic memory is an important aspect of this thesis.

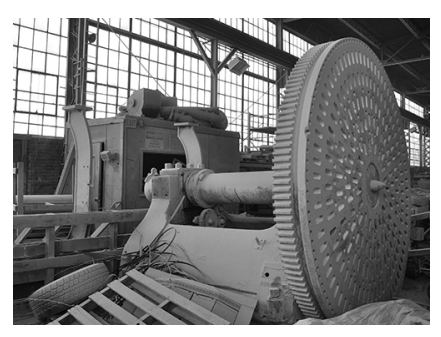

Figure 23 - the lathe that formed the White House columns

\section{Community}

The design is premised on the idea that the Creative Community Project allows its participants to connect and work with each other, opening up business opportunities and work experience that is unconventional, current and creative. All of the aspects of the programming and design are oriented to achieve this. Like MIT's building 20, this project puts students of different backgrounds together; providing common spaces for students and aspiring entrepreneurs and allowing a dialogue to emerge. Reinforcing the community-oriented idea, 
continuing education programs as well as extra-curricular programs for younger children can take place on evenings and weekends, while students of the regular day program are not using the facility.

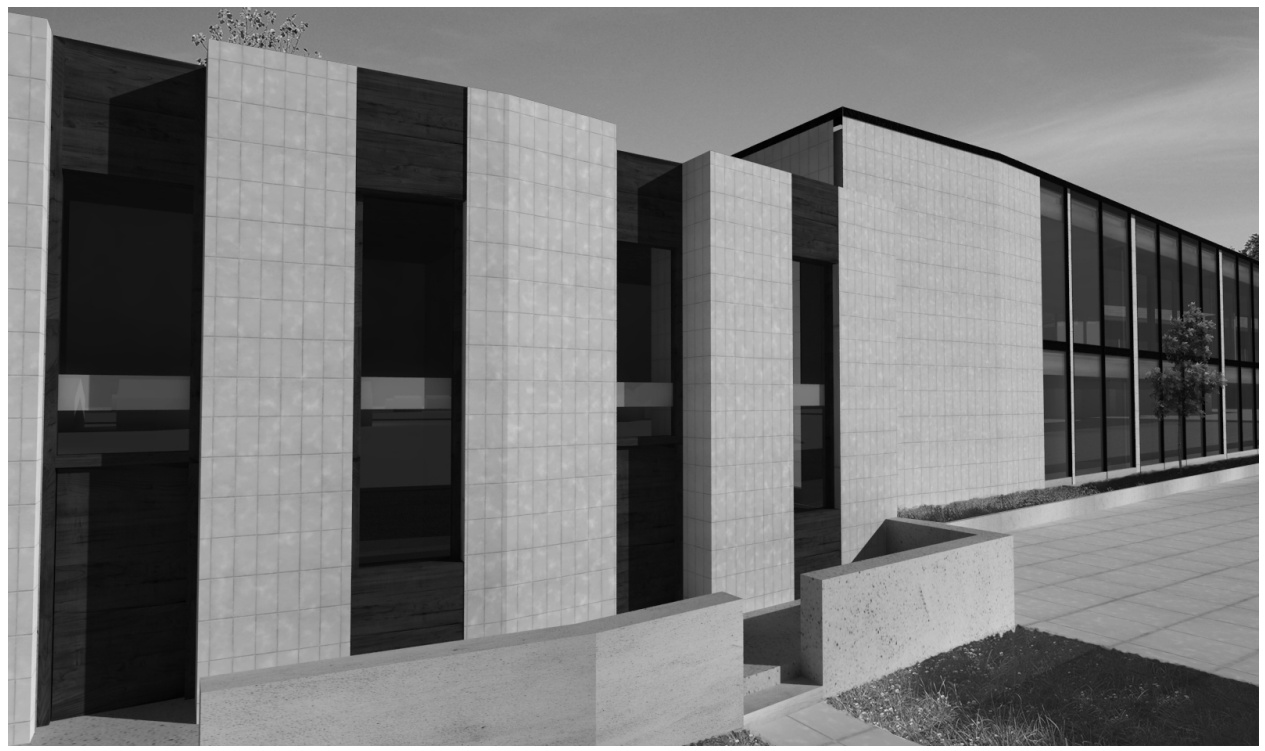

Figure 24 - townhouse residences

\section{Unique Elements}

A prototyping centre is available for the students to test their designs through fabrication. The students' work can be displayed on exhibiting feature walls that provide a venue for them to display products and designs. The second floor lecture hall provides space for presentations and exhibitions of student work, as well as a venue for visiting speakers. Residences are available to be rented by students that require living accommodations. 


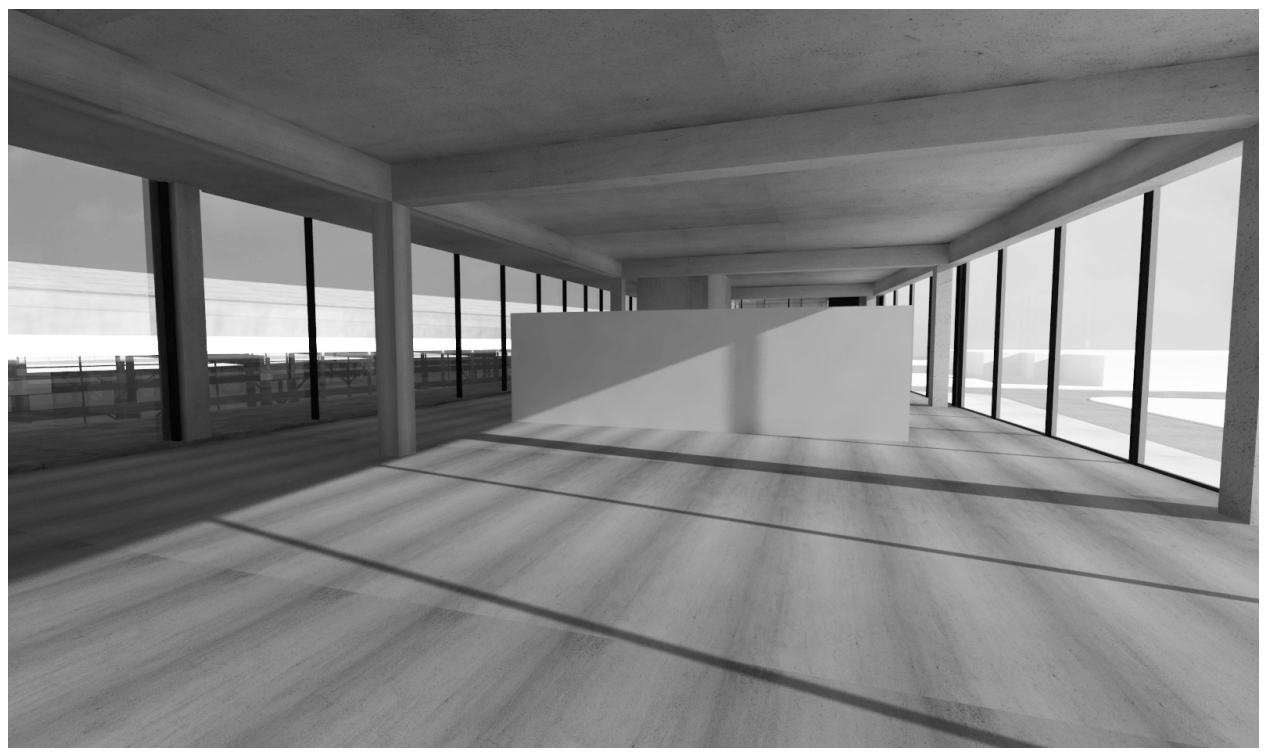

Figure 25 - lecture hall
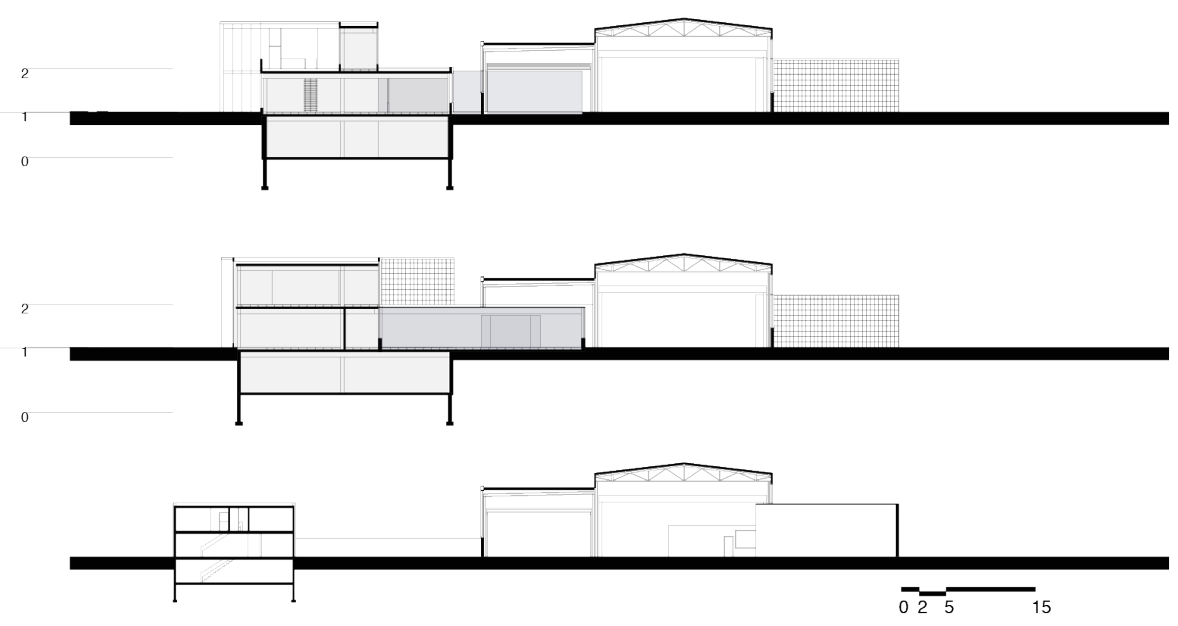

Figure 26 - from top: sections A, B and C 


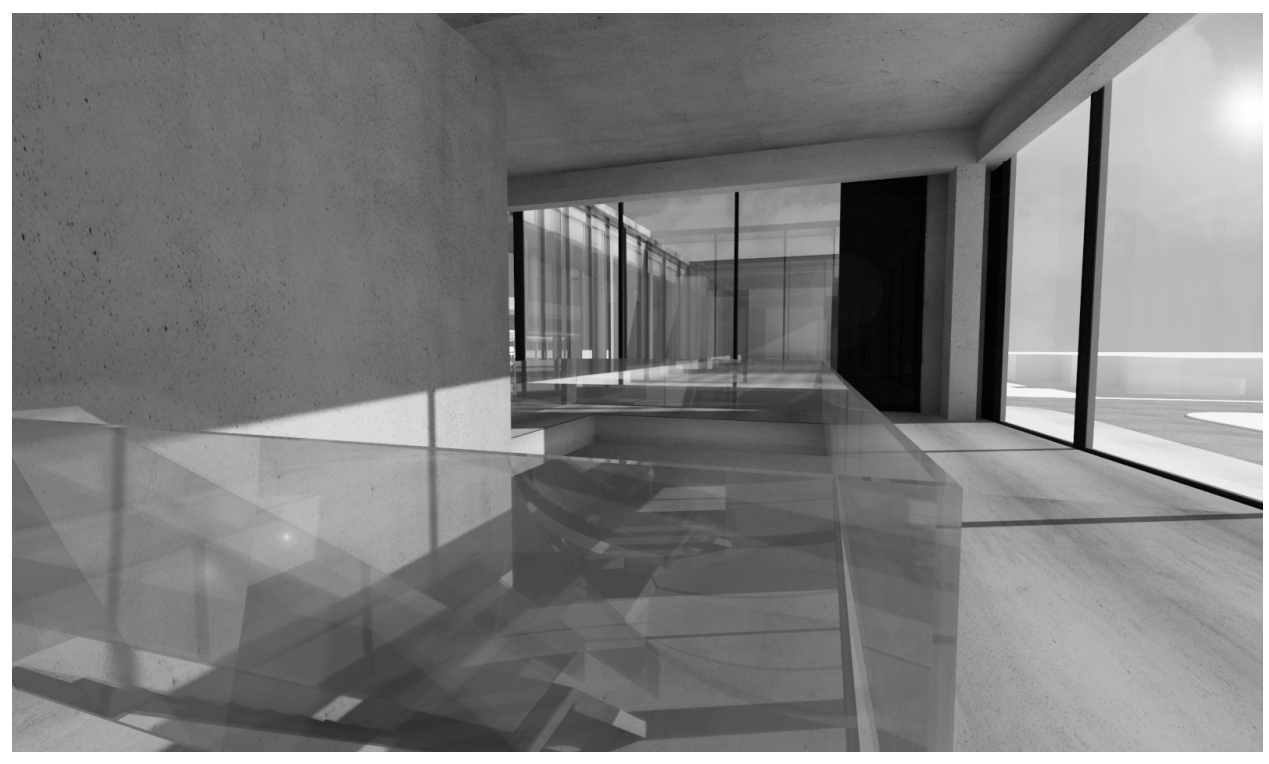

Figure 27 - circulation space 


\section{PART 4 | COMMENTARY}

This section includes:

1. A summary

2. A discussion relating to the project and the research that addresses how the design responds to the research, precedent studies and thesis position.

3. Limitations

4. Conclusions

\section{Discussion}

The themes of layering and nesting have recurred throughout the case studies and research. The factory building from which this project stems has its own spatial nesting with many layers of structural steel beams, trusses and columns being the defining aspects of the interior space. The materiality varies, with concrete, brick, glass and wood decking being unified by the dulling limestone dust.

By employing these ideas spatially in two and three dimensions, the existing structure and the new building have been interlocked. The community members have visual and physical relationships to the open and circulation spaces. An entrance lobby and wide hallway feed all of the other spaces on the ground floor. On the upper level, visual connections to the ground floor and exterior courtyard are enabled. Casual surveillance is encouraged, and the range of public and private uses and the customization of space enforce the sense of jurisdiction and ownership for users.

\section{Better Blocks}

The nature of modern suburban cities is questioned by Jason Roberts who conceptualized The Better Block Project. After travelling in Europe, he questioned the livability 
of in Oak Cliff in Dallas, Texas where he lived with his family. Some of the ideas applicable to this project are:

1. Bottom up approaches to neighbourhood rejuvenation

2. Initiatives and ideas designed to change the perception of the place

3. Creating an anchor

The goal of this project is to create a neighbourhood anchor at the site, using the business Roman Stone Works and the factory it resides in for inspiration determining how to program and articulate the site. This project is intrinsically bottom-up, using the contextual realities to define the research and the design.

\section{Adaptive Reuse and Continuity}

Often, adaptive reuse is marketed as a move towards sustainability. There is a growing interest in the dichotomy between new and old forms, often explored in cultural projects such as museums; these often have a long and sometimes architectural history of their own. Sometimes, building reuse is aesthetically motivated: it is a tool that can add a degree of complexity to a project using strategies that would both preserve and innovate (Hansen, 2003). Furthermore, this appropriation of the industrial aesthetic for the sustainable cause is motivated by the need to reestablish the importance of urban centres. The industrial image - a negative one in deindustrialized centres - becomes the image for more adaptable and therefore more resilient economic and social structures.

Adaptive Reuse is frequently done in the wake of socioeconomic shift, when industry, economy or society itself ruptures (Camocini \& Rebaglio, 2012). The definition is specific to contemporary understanding, but this phenomenon has been occurring for ages. By recognizing 
this, it becomes easier to appreciate the way architecture can engage with changing economies.

The historical preservation of architecture is important. It is often done through nonprofit organizations, and with much irritation on the part of corporations who would like to maximize real estate potential through demolition. Preservation cannot always be done at the expense of profit. In places where the economic situation is unstable, is not possible without the help of philanthropy. Alternatively, preservation should be a priority and should enhance the value of places - businesses and cities alike.

This thesis exposes the disjunctive nature of Detroit, where all the rules are broken. Whether it is residential homes next to intensive industrial uses, or vastly overgrown vacant sites, the urban structure is broken. In Detroit, there are thousands of buildings from small homes to the mammoth Michigan Central Station that are being held by land speculators waiting for the real estate value to inflate. This thesis leads to the conclusion that preservation can be accomplished by establishing symbiotic relationships between old and new architecture. The memory of places can be reinforced by the new architecture, which can initiate a conversation with the site's historic orientation, forms, or functions. In the example given by 13000 Lyndon Street in Detroit, the building is maintained while increasing its performance. The site is improved by bolstering the planning systems already in place. The sectional study and the implementation of superimposed ordering systems provides clues as to how the new and old interact, in formal and programming aspects as well as time-based factors.

\section{Limitations}

There is high level of blight and vacancy, and this project can only deal with a small portion of it. A major problem is property owners who are holding land and leaving it vacant as a long-term investment. Land speculation has had a detrimental affect on urban form and 
architecture.

Further research could delve into the political issues in the city of Detroit; race has shaped the city as much as industry, and the two are connected in complex ways. Another limitation is the recognition that the city is in bankruptcy. Projects relating to private companies in the hospitality, sporting and music industries have more agency to widen the scale of revitalization, by physically and economically injecting projects and capital. One example of a private project with a revitalization focus is Hantz Farms, which plans to purchase 200 acres of city owned land to build tree farms that will be open to the public, create jobs, and provide tax revenue to the city. This relieves the city of the maintenance costs as well, but can only go so far.

The geographic separation of demographic and economic variations is an aspect of Detroit that has and will continue to be important as the population continues to fluctuate. This project did not extend to study aspects of race and poverty as these are outside the scope of this thesis; "the ruins of the old order" (Florida, 2012 p. 400) are not just physical in Detroit, but emotional and socially complex.

This thesis touches on the design of a school and its relationship to the growth of the creative community in parallel to the existing economically successful, spatially evocative industrial building. Another limitation is that the pedagogical method could not be explored fully, as it is outside the scope of this project. The ideas of experts in the field have been noted as necessary to explain the rationale for some decisions made; in particular, Sir Ken Robinson, who is an educator and spoke on creativity and schools in the most popular TED talk ever recorded.

\section{Conclusions}

This thesis is an investigation into a site, which happens to be in one of the many post- 
industrial cities that have struggled with the changing economic climate and population dispersal. In Detroit specifically, there are thousands of examples of buildings that have been abandoned due to lost industry and tax foreclosure. The urban organization was determined by growth patterns of the modern era, and the collapse of the population greatly affects the people that still live there. A historical background of Detroit uncovered some of the cultural and artistic aspects of the city that speak to the hope that residents have in the city's longevity.

Further research could delve into the possibility that more historically significant buildings could be maintained and restored if partnered with successful businesses. If possible, traditional and new forms of craft could be involved in re-programming them. Industrial structures have a greater likelihood of being torn down, especially those that are in areas that are not densely populated. Although this design is specific to Detroit, Creative Community Projects - like the Better Block Projects - could become ubiquitous. Vibrant cities that can use older buildings in new ways, much like Jane Jacobs proposed:

"Cities need old buildings so badly it is probably impossible for vigorous streets and districts to grow without them.... for really new ideas of any kind - no matter how ultimately profitable or otherwise successful some of them might prove to be... Old ideas can sometimes use new buildings. New ideas must use old buildings" (Jacobs, 1961 p. 187-188).

In Detroit the breakdown of the old order is being replaced by flux and uncertainty (Florida, 2012). Florida argues that place is important for growing talent; Detroit has competitive schools and real estate prices to accommodate some of these place-based needs. Amenities are growing and access to cultural and sporting events is abundant. "Urban centres and walkable suburbs are the most sought-after for the creative class, and the most successful cities have technology, talent, and tolerance." (p. 11) The last is a hurdle for Detroit, where a problematic racial struggle has so defined the makeup and the atmosphere of the city. This is a limitation and a challenge, but the positive thing is that diversity and conflict are intrinsically creative. Florida 
says Detroit's ranking of $53^{\text {rd }}$ in number of Creative Class workers in the city is surprising - this thesis points to the indicators that it is not.

Florida describes the creative ethos as the character growing in our culture (Florida, 2012). Involvement in creative programming from a young age can develop the neighbourhood outlook; the success of its children can snowball to change the character of the neighbourhood. Bringing more creative people to Littlefield will allow for grassroots growth of such characteristics. Then, the place becomes more desirable to those looking to partake in a social environment where creative relationships are nurtured. The Make/Shift Creative Community Project encourages this procession. Amongst the detritus of Detroit, in spite of it, people are gathering.

Creating an anchor for the neighbourhood is the main objective and outcome of this Thesis-Project. The site extents reach to three streets in the neighbourhood of Littlefield: Lyndon Street, Cheyenne Street and Eaton Avenue. This site provides jobs, community amenities and educational opportunities for young and more mature entrepreneurs. The design adds longevity to the factory while marketing its products and providing educational opportunities for the industrial workplace. Osho stated "creativity is the greatest rebellion" (1999). The rebellion in Detroit is starting with artists and designers. In a TED Radio Hour episode called the Source of Creativity, Sting defines creativity as the ability to take a risk. Taking a chance on Detroit is risky, and it's a move that more creative people are making. 


\section{References}

Bennett, E. H. (1915). Preliminary plan of detroit. (Urban Planning). Detroit: City Plan and Improvement Commission.

Bernard tschumi architects. (2014). Retrieved March 21, 2014, from http://www.tschumi.com/ projects/featured/

Binelli, M. (2012). Detroit city is the place to be: The afterlife of an american metropolis. New York: Metropolitan Books.

Boito, C., \& Birignani, C. (2009). Restoration in architecture: First dialogue. Future Anterior, 5(1)

Build-on: Converted architecture and transformed buildings (2009). In Klanten R., Feireiss L. (Eds.), . Berlin: Gestalten.

Camocini, B., \& Rebaglio, A. (2012). Restoration economy

Detroit history. (2008). Retrieved July/16, 2014, from http://www.city-data.com/worldcities/Detroit-History.html

Fisher-Gewirtzman, D. (2012). Footprints of industrial giants

Florida, R. (2012). The rise of the creative class, revisited. New York: Basic Books.

Gensler design + performance report. (2008). United States:

Goodman, J. (2013). Rust belt renaissance: The future american city. Retrieved November/11, 2013, from http://thepolitic.org/

Hansen, M. F. (2003). The eloquence of appropriation. Analecta Romana Instituti Danici).

In detail: Building in existing fabric (2003). In Schittich C. (Ed.), . Basel: Birkhauser.

Jacobs, J. (1961). The death and life of great american cities. New York: Random House. 
Katz, D. G., \& Phillips, B. (2011). Preservation through transformation

Koestler, A. (1969). The act of creation. London: Hutchinson \& Co.

Limb, C. (2014). What does a creative brain look like? Unpublished manuscript.

Meier, H. (2011). Spolia in contemporary architecture: Searching for ornament and place. In Reuse V alue. Brilliant, \& D. Kinney (Eds.), England: Ashgate.

Mokyr, J. (1990). The lever of riches: Technological creativity and economic progress. New York: Oxford University Press.

Molloy, J. C. (2014). Can architecture make us more creative? Retrieved July/11, 2014, from www.archdaily.com

Newman, O. (1973). Defensible space: Crime prevention through urban design. New York, NY: Macmillan Publishing Co., Inc.

Osho. (1999). Creativity: Unleashing the forces within. New York: St. Martin's Griffin.

Pineau, N., \& Boldarini, M. e. a. (2013). a $+\mathrm{t} \mid$ reclaim - remediate, reuse, recycle. $A+t$ Architecture Publishers, 39-40(Spring/Autumn)

Pofeldt, E. (2013, May 27). U.S. entrepreneurship hits record high. Forbes

Reader, J. (2004). Cities (1st American ed. ed.). New York: Atlantic Monthly Press.

Reuse value: Spolia and appropriation in art and architecture, from constantine to sherrie levine (2011). In Brilliant R., Kinney D. (Eds.), . Burlington, VT: Ashgate.

Roberts, J. (2012). How to build a better block.

Robinson, K. (2014). How do schools kill creativity? Unpublished manuscript. 
Schittich, C. (2013). Editorial. Detail: Review of Architecture and Construction Details, 2013(3)

Seydel, O. (2013). Places of learning and living - requirements for full-time schools. Detail: Review of Architecture and Construction Details, 2013(3)

Stern, M. (2005). Pittsburgh forges ahead: Brownfields are becoming the economic drivers of a postindustrial landscape. Urban Land, 64(6), 114-115,124-126.

Sugrue, T. J. (1996). The origins of the urban crisis: Race and inequality in postwar detroit. Princeton, NJ: Princeton University Press.

Thiebault, P. (2007). Old buildings looking for new use: 64 examples from europe. Stuttgart: Axel Menges.

Transformer (2010). In Shaoqiang W. (Ed.), . USA: Gingko Press.

Tschumi, B. (1996). Architecture and disjunction (1st MIT Press pbk. ed. ed.). Cambridge, Mass.: MIT Press.

Uffelen, C. v. (2011). Re-use architecture. (1st ed. ed.). Salenstein, Switzerland: Braun.

Waugh, E. (2012). Recycling spaces: Curating urban evolution ORO editions.

Wollen, P., \& Kerr, J. (Eds.). (2002). Autopia: Cars and culture. London: Reaktion Books Ltd.

Zumpthor, P. (1999). Thinking architecture. Boston: Birkhäuser. 